\title{
Emergency First Responders' Experience With Colorimetric Detection Methods
}

Sandra L. Fox

Keith A. Daum

Carla J. Miller

Marnie M. Cortez

October 2007

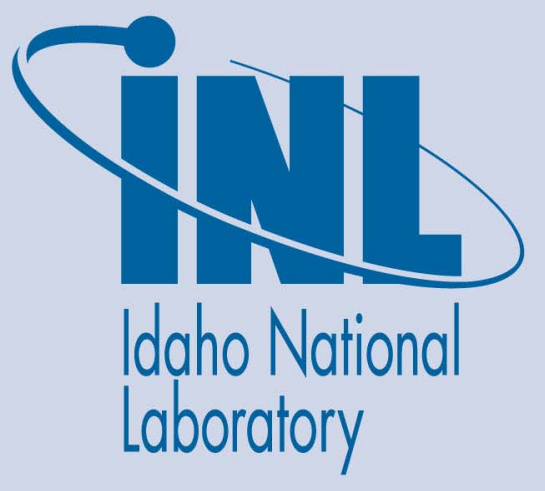

The INL is a U.S. Department of Energy National Laboratory operated by Battelle Energy Alliance 


\title{
Emergency First Responders' Experience With Colorimetric Detection Methods
}

\author{
Sandra L. Fox \\ Keith A. Daum \\ Carla J. Miller \\ Marnie M. Cortez
}

October 2007

Idaho National Laboratory
Idaho Falls, Idaho 83415

Prepared for the

U.S. Department of Homeland Security

Under DOE Idaho Operations Office

Contract DE-AC07-05ID14517 


\section{DISCLAIMER}

This report was prepared as an account of work sponsored by an agency of the U.S. Government. Neither the U.S. Government nor any agency thereof, nor any employee, makes any warranty, expressed or implied, or assumes any legal liability or responsibility for any third party's use, or the results of such use, or any information, apparatus, product, or process disclosed in this publication, or represents that its use by such third party would not infringe privately owned rights. 



\section{Emergency First Responders' Experience with Colorimetric Detection Methods}

INL/EXT-07-12644

October 2007

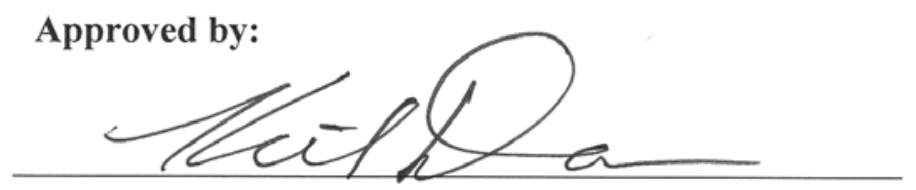

Keith A. Daum, PhD

Project Manager 



\begin{abstract}
Nationwide, first responders from state and federal support teams respond to hazardous materials incidents, industrial chemical spills, and potential weapons of mass destruction (WMD) attacks. Although first responders have sophisticated chemical, biological, radiological, and explosive detectors available for assessment of the incident scene, simple colorimetric detectors have a role in response actions. The large number of colorimetric chemical detection methods available on the market can make the selection of the proper methods difficult. Although each detector has unique aspects to provide qualitative or quantitative data about the unknown chemicals present, not all detectors provide consistent, accurate, and reliable results. Included here, in a consumer-report-style format, we provide "boots on the ground" information directly from first responders about how well colorimetric chemical detection methods meet their needs in the field and how they procure these methods.
\end{abstract}




\section{EXECUTIVE SUMMARY}

In support of the U.S. Department of Homeland Security (DHS) Standards Portfolio, Idaho National Laboratory (INL) collected information directly from users about their experience with chemical detection methods. The goal was to obtain a cross-sectional understanding of how colorimetric detectors are used in the field by acquiring "boots on the ground" information. A survey was completed to determine how first responders select and use chemical detection equipment. This process allowed first responders to provide feedback on the entire process from selection and procurement through use in the field. Fourteen HazMat (Hazardous Materials) teams representing the western, central, and eastern regions of the U.S. were interviewed to learn how well colorimetric methods meet their first response needs. The regional populations ranged from less than 100,000 to major metropolitan areas. In brief, we learned the following:

1. Colorimetric technologies are valued by the first responder because they are inexpensive, simple to use, and can aid in determining the extent of a potential threat.

2. In all the populations surveyed, colorimetric technologies account for nearly $50 \%$ of the total number of chemical detection methods HazMat professionals own.

3. There are over 50 colorimetric detection methods available on the market, yet of the populations surveyed, only 12 colorimetric methods were identified as being used by their HazMat professionals.

4. Colorimetric methods are seldom used as part of an integrated system for detecting and identifying chemicals. Instead, they are often used independently or as a simple confirmatory analysis.

5. Although the deciding factor in choosing an instrument for the incident scene is situation dependent, commonly used instruments like radiation meters, multiple gas meters, photoionization detectors, and $\mathrm{pH}$ paper were the initial types of detectors used at an incident.

6. HazMat teams are confused about the capabilities of gas detection tubes, with even major metropolitan areas having difficulty correcting for temperature and humidity. One larger city uses a newer electronic chip technology, which is more quantitative and may be replacing the tubes.

7. Most HazMat professionals use colorimetric tubes for qualitative analysis, not for quantification.

8. $\mathrm{pH}$ paper is universally used as an initial indicator by HazMat professionals because classifying unknown chemicals as acidic or basic is an important initial consideration.

9. All cities interviewed use a follow-up detection method to confirm results when analyzing an unknown at an incident scene. 


\section{ACKNOWLEDGMENTS}

We would like to thank the HazMat professionals who allowed us to interview them. The names of the cities and individuals interviewed were intentionally omitted to increase the possibility of more complete responses. 


\section{CONTENTS}

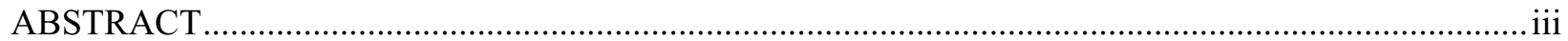

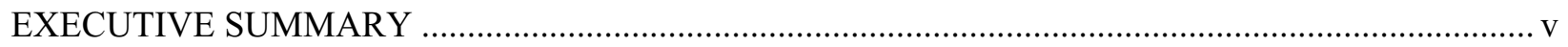

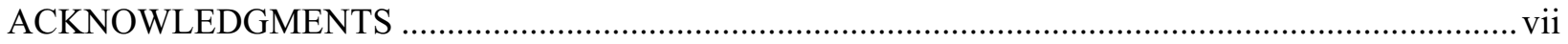

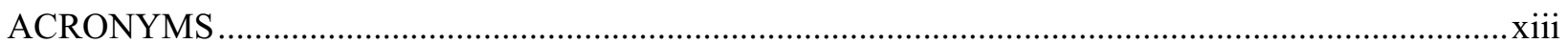

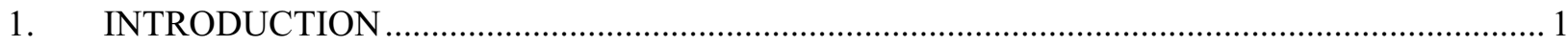

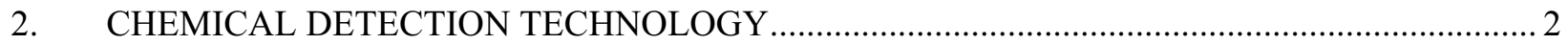

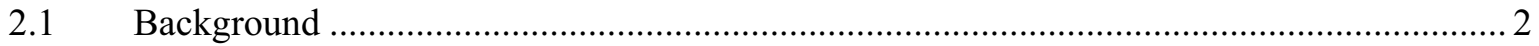

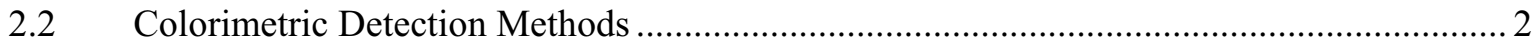

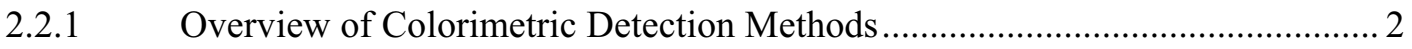

2.2.1.1 Litmus and $\mathrm{pH}$ Papers.................................................................. 3

2.2.1.2 M8/M9 Chemical Detection Papers.............................................. 3

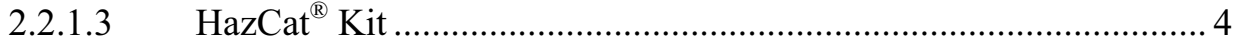

2.2.1.4 M256A1 Chemical Agent Detector Kit....................................... 4

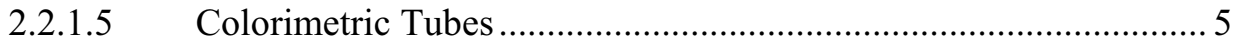

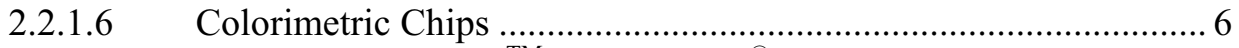

2.2.1.7 HazMat Smart-Strip ${ }^{\mathrm{TM}}$ and Spilfyter ${ }^{\circledR}$ Chemical Classifier

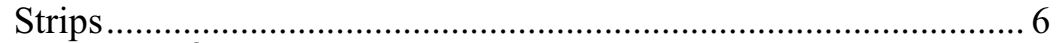

2.2.1.8 Chameleon ${ }^{\circledR}$ Chemical Detection Device ........................................ 7

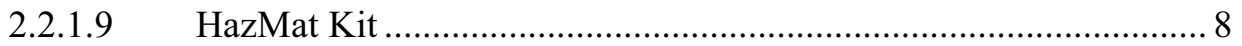

2.2.1.10 Heinz 5-Step ${ }^{\mathrm{TM}}$ Field Identification Method ................................ 8

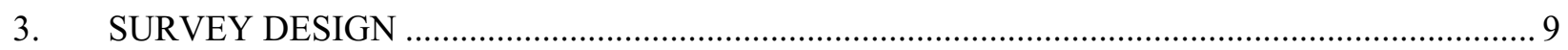

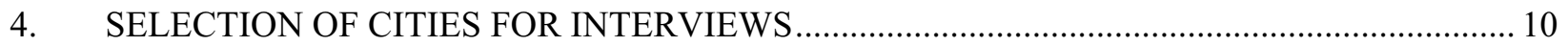

5. SUMMARY OF INTERVIEW RESPONSES FROM HazMat PROFESSIONALS ...................... 11

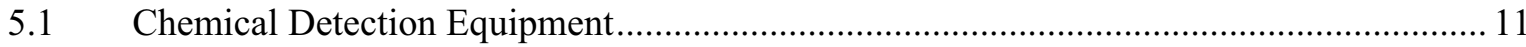

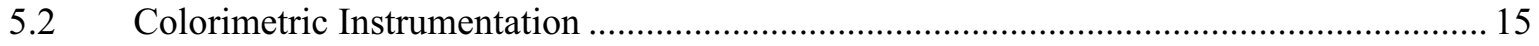

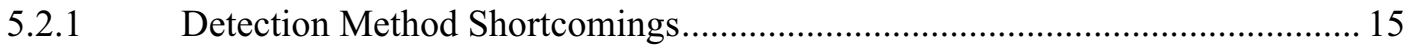

5.2.2 Overcoming Some of the Shortcomings of Colorimetric Detection

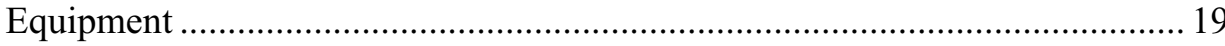

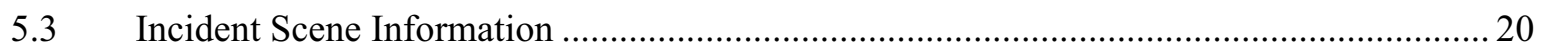

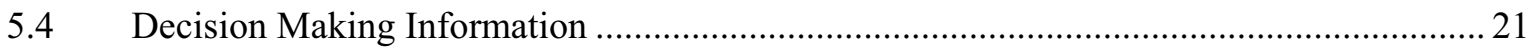

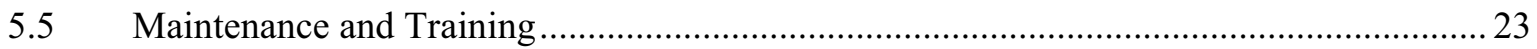




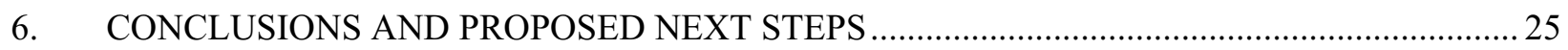

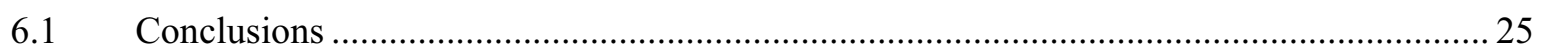

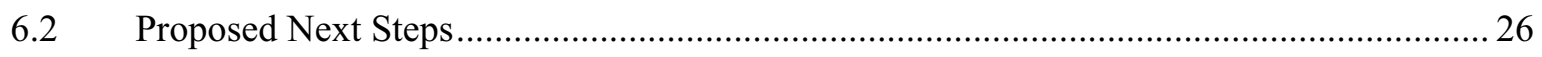

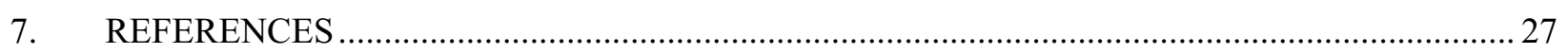

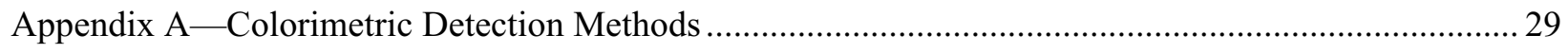

\section{FIGURES}

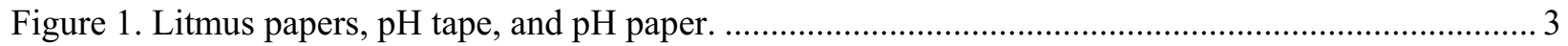

Figure 2. The HazCat ${ }^{\circledR}$ Kit by HazTech Systems $^{\mathrm{TM}}$, Inc. ............................................................. 4

Figure 3. M256A1 Chemical Agent Detector Kit contents................................................................... 5

Figure 4. Colorimetric tubes and a detailed schematic of the tubes..................................................... 5

Figure 5. Draeger Safety, Inc.'s Chip Measurement System and an example of the chips used................. 6

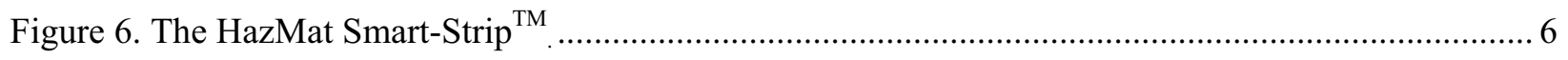

Figure 7. The Spilfyter ${ }^{\circledR}$ Chemical Classifier test strips and color chart. …........................................ 7

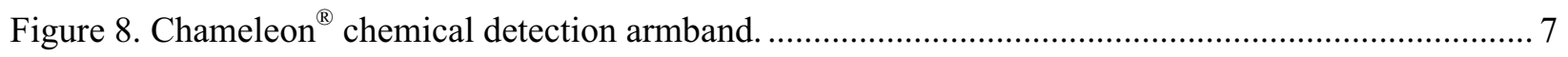

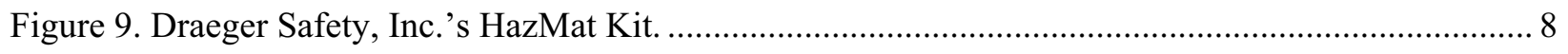

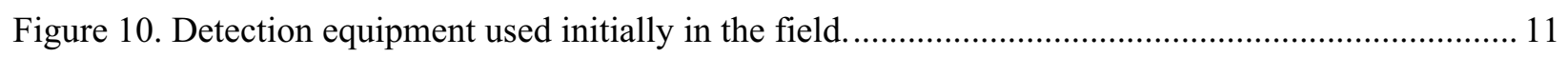

Figure 11. Total chemical detection technologies owned, based on size of city. ................................... 12

Figure 12. Colorimetric detector rating ( 1 is low, 5 is high) based on geographic region......................... 20

Figure 13. Distribution of how first responders dealt with a false positive or negative. .......................... 21

Figure 14. Percentage of first responders responsible for selecting instruments, based on region............. 22

Figure 15. Percentage of first responders responsible for selecting instruments, based on

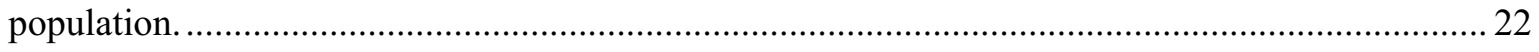

Figure 16. Distribution of who provides chemical detection instrument training based on

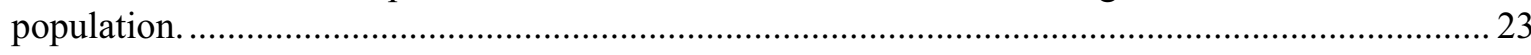

Figure 17. Percentage of responders who thought the manufacturers' data was realistic......................... 24 


\section{TABLES}

Table 1. Use of colorimetric detection technology by first responders. .................................................. 13

Table 2. List of shortcomings of colorimetric technology as identified by HazMat professionals. ........... 16

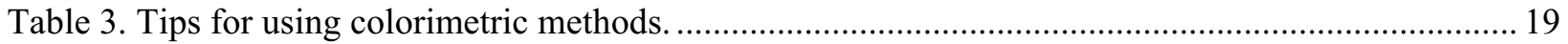




\section{ACRONYMS}

\begin{tabular}{ll} 
CAD & Chemical Agent Detector \\
CAM & Chemical Agent Monitor \\
CGI & Combustible Gas Indicator \\
CMS & Chemical Measurement System \\
CW & Chemical Warfare \\
DHS & U.S. Department of Homeland Security \\
FID & Flame Ionization Detector \\
FT-IR & Fourier Transform Infrared \\
GC/MS & Gas Chromatography/Mass Spectrometry \\
HazCat & Hazard Characterization \\
HazMat & Hazardous Materials \\
IMS & Ion Mobility Spectrometry \\
INL & Idaho National Laboratory \\
IR & Infrared \\
PID & Photoionization Detector \\
RAD & Radiation \\
SAW & Surface Acoustic Wave \\
WMD & Weapons of Mass Destruction \\
\hline
\end{tabular}




\section{Emergency First Responders' Experience with Colorimetric Detection Methods}

\section{INTRODUCTION}

The U.S. Department of Homeland Security (DHS) is interested in assuring that emergency first responders have appropriate measurement technologies for evaluating incident scenes. Idaho National Laboratory (INL) was given the task of evaluating the experience of first responders with colorimetric chemical detection methods. The goals were to obtain cross-sectional experience with colorimetric methods by obtaining input directly from users in order to provide "boots on the ground" information about selection and use of equipment in order to guide future equipment research and development and improve processes for procurement of the equipment. Most first responders have access to a wide range of chemical detectors to assess an incident scene. Detectors provide different types of qualitative or quantitative data about the unknown chemicals present; however, not all detectors provide consistent, accurate, and reliable results. This report provides information to help DHS establish guidelines and standards to assist first responders in selecting field instruments necessary to make rapid and reliable decisions.

Colorimetric detection methods are the focus of this consumer-reports-style summary. Information about colorimetric methods and first-hand information from users were compiled. HazMat (Hazardous Materials) professionals representing cities of various population size and different regions from across the U.S. were selected and then contacted by telephone. Through a set of targeted questions developed by INL, HazMat professionals helped identify colorimetric detection equipment, detailed their experience on colorimetric usage, identified limitations of colorimetric detection methods, explained how equipment decisions are made, and provided perspectives on how well these instruments meet their first-response needs. Other sections of this report briefly describe available colorimetric methods and how they are used at an incident scene. 


\section{CHEMICAL DETECTION TECHNOLOGY}

\subsection{Background}

Currently, there are several hundred chemical detection instruments available on the DHS Authorized Equipment List (AEL) for emergency first responders. These chemical detection technologies cover a range of fundamental processes from color change reactions to selective ionization, ion mobility, and spectroscopy. The first responder relies on one or more of these chemical detection technologies to assess the incident scene and make critical decisions. Even though emergency first responders may have a number of different chemical detection technologies at their disposal, all of the equipment they have available may not be fully used. The first responder is often provided a piece of equipment that was obtained through the DHS grant system; however, some of these detectors are used on a limited basis or not at all.

First responders use chemical detectors to make field decisions. Usually these field decisions involve classifying, identifying, or quantifying an unknown chemical. Some chemical detection methods are designed to classify chemicals into broad categories, such as aromatics or chlorine containing gases. These methods are often more rapid and are used for preliminary analysis. Other detection methods are more selective and can reliably detect a specific chemical. These methods are used to determine if a chemical is above or below some target concentration, which is often set based on health standards. Detection methods can also be quantitative and provide an estimate of the amount or quantity of the chemical present. First responders must choose the detection methods that they use to give a balance among the need for rapid classification, reliable identification, and quantification.

This report focuses on obtaining feedback from first responders to determine which colorimetric detection methods are used and identify potential limitations of the instrumentation to aid DHS in developing standards for chemical detection equipment.

\subsection{Colorimetric Detection Methods}

\subsubsection{Overview of Colorimetric Detection Methods}

Colorimetric detection methods indicate the presence of a chemical agent through a chemical reaction that results in a color change. The color change may either be detected visually or may rely on spectrophotometric instrumentation. The following colorimetric methods, widely used by the HazMat professionals we interviewed, are described in this section: Litmus and $\mathrm{pH}$ papers, M8/M9 chemical detection papers, HazCat ${ }^{\mathbb{B}}$ Kit, M256A1 Chemical Agent Detector Kit, colorimetric tubes and chips, HazMat Smart-Strip ${ }^{\mathrm{TM}}$, Spilfyter ${ }^{\circledR}$ Chemical Classifier Strips, Chameleon ${ }^{\circledR}$ chemical detection device, Draeger HazMat Kit, and the Heinz 5-step ${ }^{\mathrm{TM}}$ Field Identification Method. ${ }^{\mathrm{a}}$ A more detailed listing of colorimetric detections methods is available in Appendix A. The colorimetric method descriptions in this report are derived from manufacturer information available online, in manuals and brochures, and from personal phone calls.

\section{a. PRODUCT DISCLAIMER}

References herein to any specific commercial product, process, or service by trade name, trademark, manufacturer, or otherwise, does not necessarily constitute or imply its endorsement, recommendation, or favoring by the U.S. Government, any agency thereof, or any company affiliated with Idaho National Laboratory. 


\subsubsection{Litmus and $\mathrm{pH}$ Papers}

Litmus and $\mathrm{pH}$ papers are used to characterize the relative acidity or basicity of a substance based on color change. Litmus is a mixture of water-soluble dyes extracted from natural products. At a $\mathrm{pH}$ below 4.6, litmus turns red, and at $\mathrm{pH}$ above 8.4, it turns blue. Between these $\mathrm{pH}$ values, litmus is generally a light purple. This wide range between color changes limits use in determining specific $\mathrm{pH}$ values. There are numerous other indicators of $\mathrm{pH}$ change with both specific and wide ranges that can be used to determine the exact $\mathrm{pH}$ of a solution. General purpose $\mathrm{pH}$ paper provides a quick and effective $\mathrm{pH}$ determination. The strip or tape containing the $\mathrm{pH}$ indicator is first dipped into a liquid, and then the resulting color change is compared to the color chart provided to determine $\mathrm{pH}$ levels. Figure 1 shows an example of $\mathrm{pH}$ paper and litmus paper. There are various vendors for both paper types, and these items can be obtained from any chemical supply company.
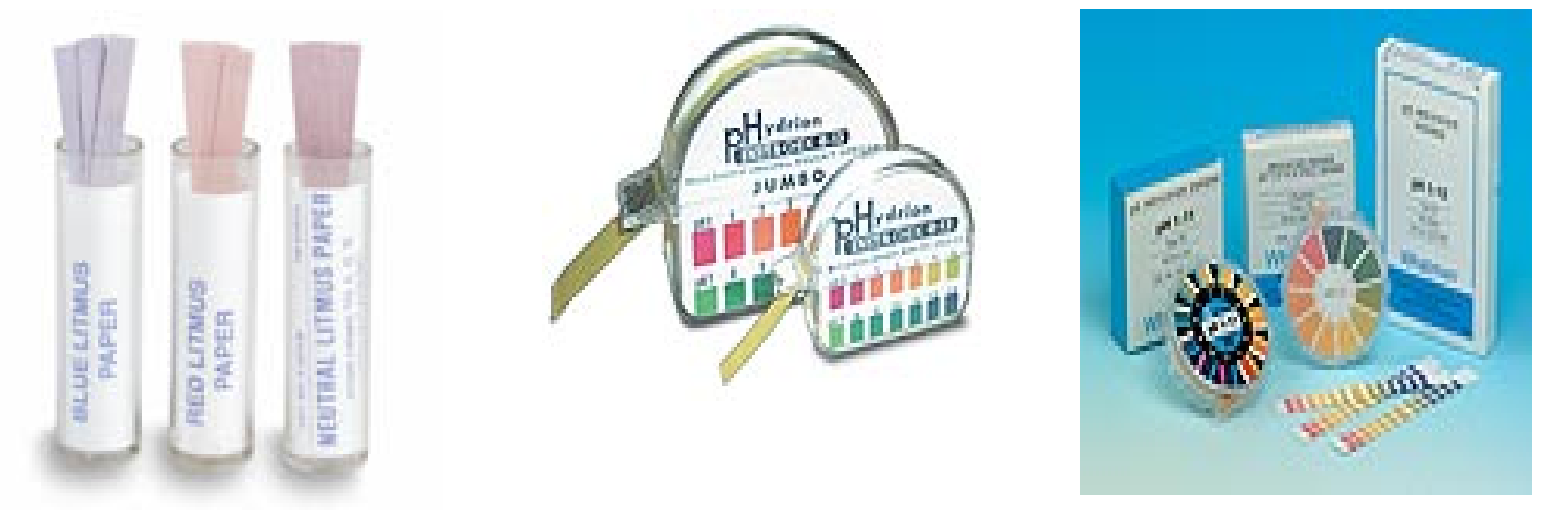

Photos courtesy of Fisher Scientific (new.fishersci.com)

Figure 1. Litmus papers, $\mathrm{pH}$ tape, and $\mathrm{pH}$ paper.

\subsubsection{M8/M9 Chemical Detection Papers}

M8/M9 chemical detection papers (Tradeways, ApprovedGasMasks.com) were originally developed for the military to detect liquid nerve and blister agents. These papers are also used by HazMat response teams and are available commercially. M8 paper is a chemically-treated, dye-impregnated paper used to detect liquid substances for the presence of V- and G-type nerve agents and H- and L-type blister agents. These papers contain three soluble dyes integrated into cellulose fiber strips. Each dye only reacts with one of the agents, producing a particular color within about 30 seconds. The paper is only sensitive to liquids, not vapors. Exposure to a blister agent turns the paper red, G-type nerve agents turn the paper yellow, and V-type nerve agents turn the paper dark green. Agents do not react directly with the dyes in M8 paper, but rather, dyes react to the unique acidity of each of the agents to produce the color change in a manner similar to litmus. Chemical detection with M8 is prone to false-positive readings from some common chemicals, such as antifreeze, insect repellents, and brake fluid. M8 paper can be used indefinitely as long as it is kept dry.

The M9 papers contain a single dye that reacts with almost any chemical agent. M9 papers react more rapidly than M8 papers and detect the same agents, but will not differentiate among the nerve and blister agents. M9 paper comes in a single roll, $10 \mathrm{~m}$ long $\times 5 \mathrm{~cm}$ wide, with Mylar-adhesive backing, which allows it to be attached to clothing and equipment for use as a detector for liquid chemical agents. M9 paper has a three-year shelf life if unopened and a six-month shelf life if opened. 


\subsubsection{HazCat ${ }^{\circledR}$ Kit}

The HazCat ${ }^{\circledR}$ Kit, manufactured by HazTech Systems ${ }^{\mathrm{TM}}$, Inc., is designed specifically for field use to perform wet chemistry techniques to classify a chemical. Figure 2 shows the components of the kit, which are self-contained in a portable, sturdy case and include a step-by-step instruction manual and logic charts for analysis of unknown chemicals. The kit can be ordered with or without colorimetric detector tubes and includes the reagents needed to test for a wide variety of inorganic and organic chemicals.

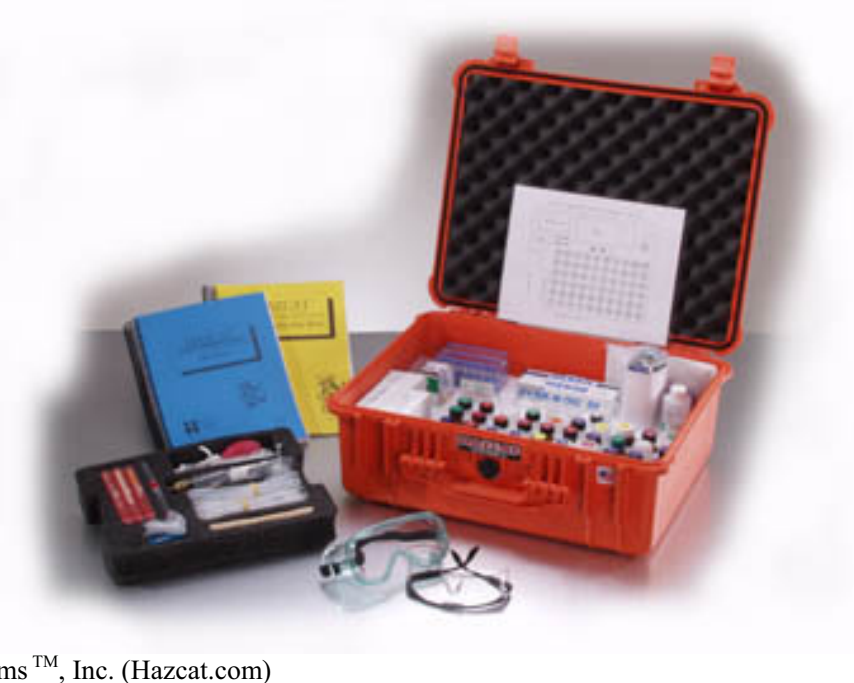

Photo courtesy of HazTech Systems ${ }^{\mathrm{TM}}$, Inc. (Hazcat.com)

Figure 2. The HazCat ${ }^{\circledR}$ Kit, manufactured by HazTech Systems ${ }^{\mathrm{TM}}$, Inc.

\subsubsection{M256A1 Chemical Agent Detector Kit}

M256A1 Chemical Agent Detector Kit (Anachemia, Canada) is used for the detection of blister, blood, and nerve agents. It was originally designed for the U.S. military and is typically used after a chemical attack to determine if the level of personal protection can be reduced or if it is safe to unmask. The M256A1 Chemical Agent Detector Kit is shown in Figure 3 and is contained in a $7 \times 5 \times 3$-in. plastic carrying case. The kit contains 12 vapor-samplers, M8 detector paper, and instruction cards. The vapor samplers are sealed in an individual plastic laminated foil envelope, used once, and then discarded. Each vapor sampler holds five test components used in an analysis: (1) glass ampoules, (2) a hinged heater assembly, (3) three test spots, (4) a hinged protective strip, and (5) a lewisite-detecting tablet with a rubbing tab. The glass ampoules contain known reagents that react with the chemical agent vapors. The two glass heater ampoules are used with the heater assembly to detect the blister agents. There are three labeled test spots on each sampler, each a different shape, made from a different material for a specific analysis. The blister agent test spot is square and made of chromatographic media; the blood agent test spot is round and made of a glass fiber filter; and the nerve agent spot is star-shaped and made from filter paper. The expected color changes are printed above each test spot and take about 15 to 25 minutes to occur. A protective strip is hinged to the sampler over the blood and nerve agent test spots to protect them from accidental contamination. The lewisite detection tablet is covered by a protective plastic pull tab that must be removed before use. False readings may occur under high temperatures and when exposed to petroleum products. The M8 paper in the kit has been previously described in the M8/M9 paper discussion. 


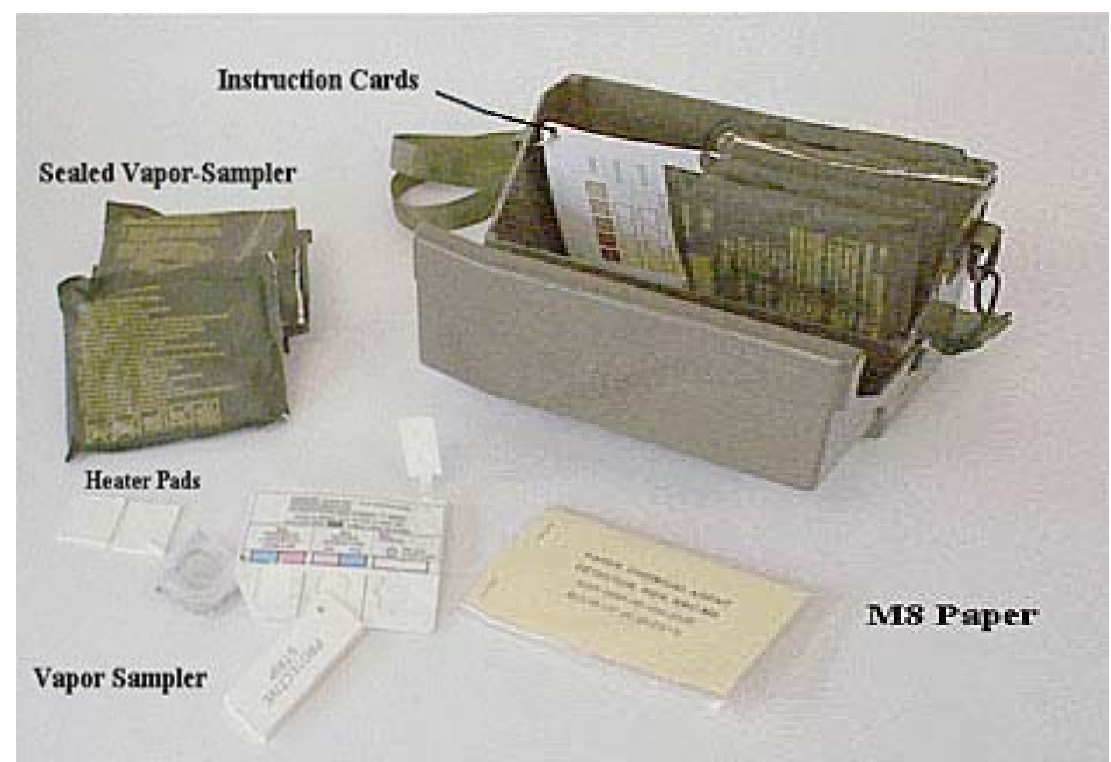

Photo courtesy of National Homeland Security Knowledgebase (twotigersonline.com)

Figure 3. M256A1 Chemical Agent Detector Kit contents.

\subsubsection{Colorimetric Tubes}

Colorimetric tubes (Draeger, MSA, Sensidyne, Gastec, RAE Systems, and Matheson) use chemical and enzymatic reactions to identify over 300 different gases, vapors, and aerosols. Figure 4 shows a detailed schematic and example of colorimetric tubes. To use colorimetric tubes, the two sealed ends are broken open, then one end of the tube is placed on the hand pump and the other end allows the air to be pulled through the tube. The tube contains a solid granular material that has been impregnated with the appropriate reagent. A specified number of pump strokes is required for each tube type in order to achieve a sufficient volume of air so that a pre-determined concentration of analyte can be determined. The concentration of the substance can be read from the tube, and a positive identification of a chemical or classes of air contaminants can be made by observing the color change in the tube. The color change normally occurs within two minutes. Some tubes are selective for a particular analyte, while other tubes can detect several analytes that all initiate the same color-change reaction in the tube. For detecting a single analyte, the concentration may be falsely inflated by the presence of other similar analytes.
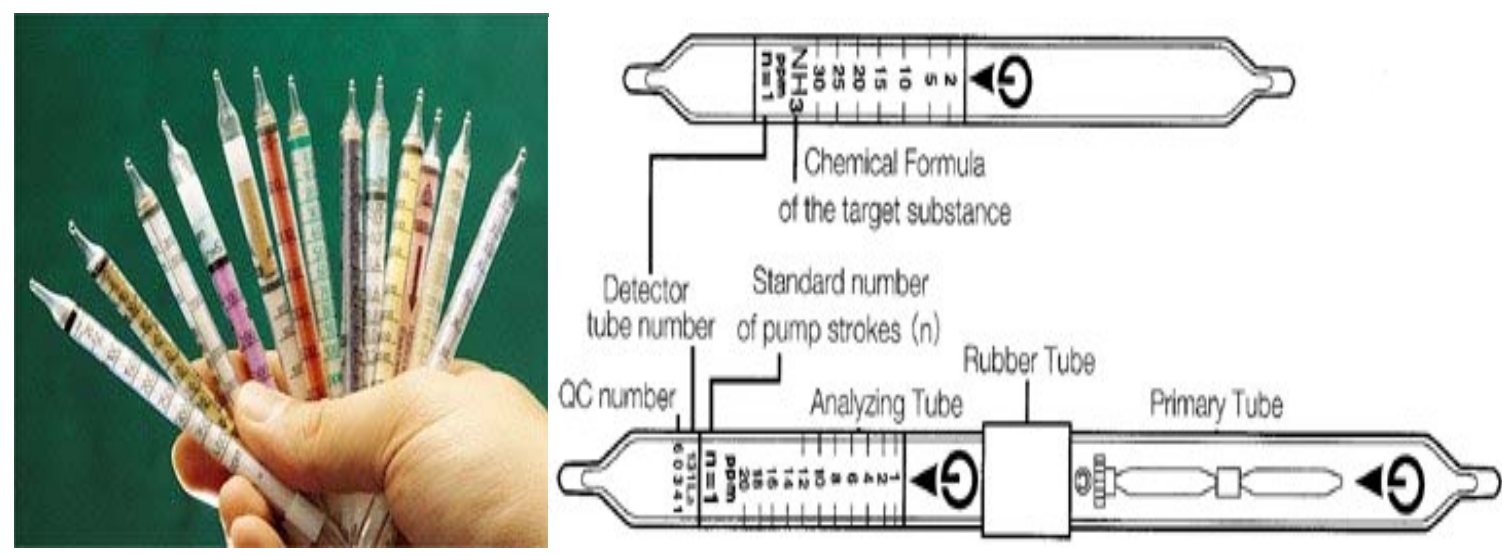

Photo and schematic courtesy of Environmental Equipment and Supply (envisupply.com)

Figure 4. Colorimetric tubes and a detailed schematic of the tubes. 


\subsubsection{Colorimetric Chips}

The Chip Measurement System (CMS), manufactured by Draeger Safety, Inc., applies the concept of colorimetric tubes to an electronic chip analyzer that integrates an optical system, a flow controller, and a pump (Figure 5). About 50 different chemicals in gases and vapors can be measured, depending on the chip inserted. Each chip contains 10 individual measurement capillaries, which are filled with a substance-specific reagent. The CMS pulls the same mass of air through the capillary each time, with the mass flow controller automatically compensating for changes in atmospheric pressure, thereby providing accuracies of $+/-4$ to $10 \%$. The gas type, part number, and batch number are printed on the chip. In addition, the calibration information for the specific gas, measuring range, and measuring time is stored on a barcode located on the chip. CMS chips have a two-year shelf life.
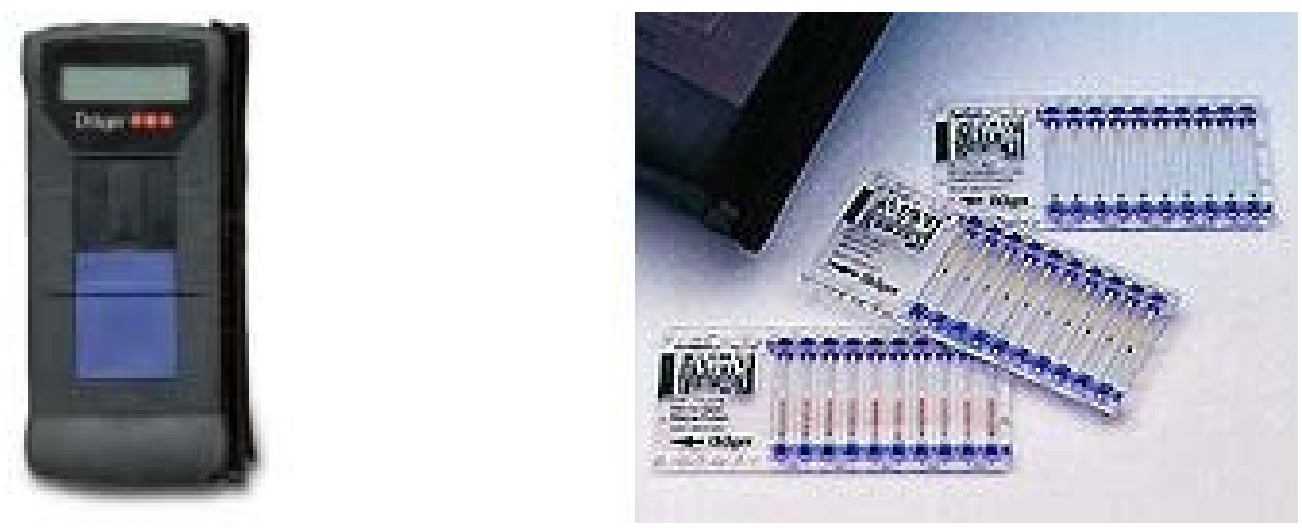

Photo courtesy of Draeger Safety, Inc. (draeger.com)

Figure 5. Chip Measurement System and examples of the chips used, by Draeger Safety, Inc.

\subsubsection{HazMat Smart-Strip ${ }^{T M}$ and Spilfyter ${ }^{\circledR}$ Chemical Classifier Strips}

HazMat Smart-Strip ${ }^{\mathrm{TM}}$ (Figure 6), manufactured by Safety Solutions, Inc., is the size of a baseball card and can be attached to clothing or other items with either a peel-and-stick adhesive strip or with a clip, such as those used for identification badges. The card is activated when a protective film is peeled from the detection area of the card. The strips are effective for about 12 hours after being opened or until they are exposed to one of the eight detected substances. A color change occurs when exposed to chlorine, $\mathrm{pH}$, fluoride, nerve agents, oxidizers, arsenic, sulfides, or cyanide in liquid or aerosol form. The strip has a two-year shelf life.

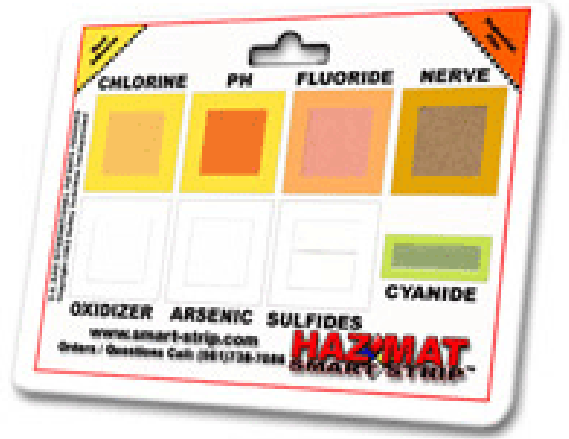

Photo courtesy of Test Medical Symptoms @ Home (testsymptomsathome.com)

Figure 6. The HazMat Smart-Strip ${ }^{\mathrm{TM}}$. 
The Spilfyter ${ }^{\circledR}$ Chemical Classifier Test Strip (Figure 7) detects classes of chemicals like acids and bases, oxidizers, fluoride, petroleum products, organic solvents, iodine, bromine, and chlorine. The color changes take place immediately, and the strip is compared to the color chart to make a determination of the chemical class present. The strips are available in kits, which include test strips, a bobbin of polypropylene thread, and a laminated Chemical Classifier Chart.

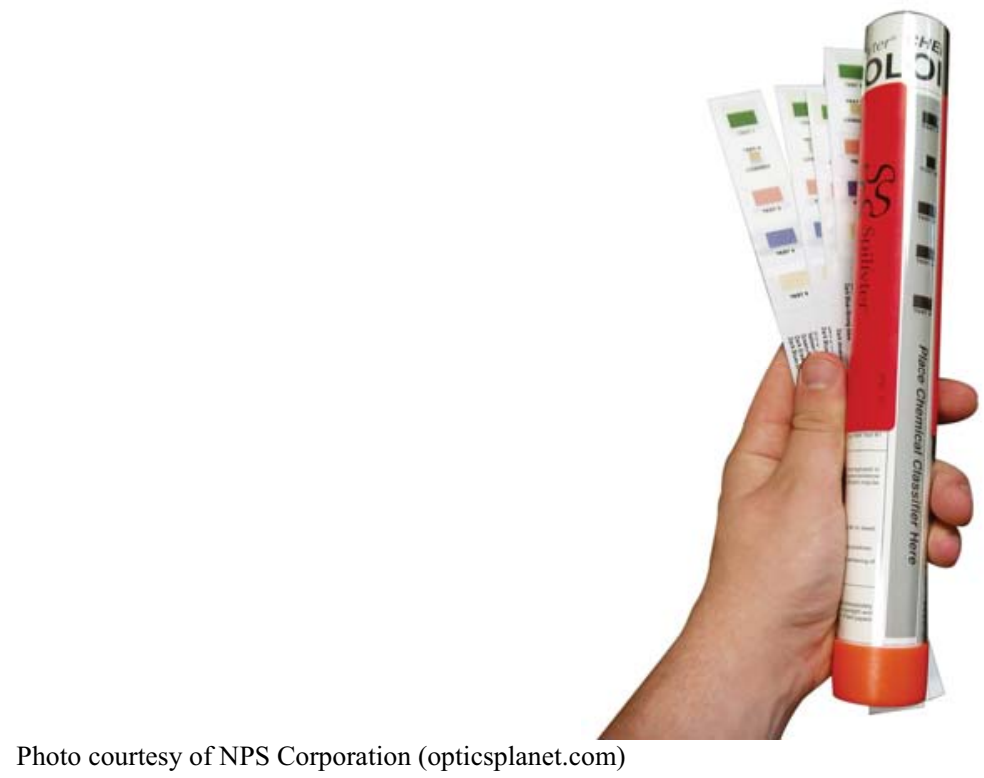

Figure 7. The Spilfyter ${ }^{\circledR}$ Chemical Classifier test strips and color chart.

\subsubsection{Chameleon ${ }^{\circledR}$ Chemical Detection Device}

The Chameleon ${ }^{\circledR}$ chemical detection device integrates colorimetric technology into an armband for detecting chemical gases and vapors. The stretchable armband holds up to 10 chemical cassettes and fits over Level-A personal protection suits. The chemical sensor in the cassette changes colors when the cassette is exposed to low $\mathrm{pH}$, high $\mathrm{pH}$, chlorine/fluorine, hydrogen sulfide, iodine, phosphine, phosgene, or sulfur dioxide. Only half of the sensor window will change color, as can be seen in Figure 8 . The armband is reusable, but the cassettes need to be discarded and replaced with new cassettes after a color change or 24 hours of use. The shelf life for the cassettes is 12 months at room temperature.

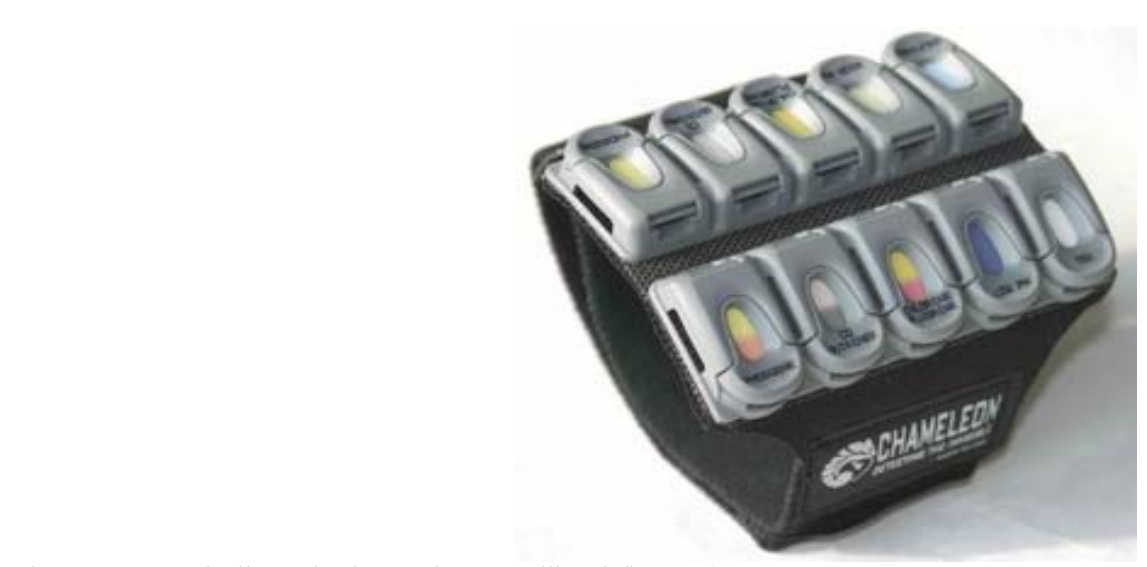

Photo courtesy of All Hands Fire Equipment (allhandsfire.com)

Figure 8. Chameleon ${ }^{\circledR}$ chemical detection armband. 


\subsubsection{HazMat Kit}

The HazMat Kit (Figure 9), manufactured by Draeger Safety, Inc., includes colorimetric detector tubes that can be customized to identify and measure chemicals in select gases and vapors. The HazMat Kit uses detector tubes in a specific sequence to obtain information about a chemical group to which an unknown substance may belong. The kit is contained in a lightweight plastic case and includes the following items: (1) Draeger Accuro Pump, (2) spare pump parts, (3) air current kit, (4) 17 detector tubes, and (5) a 3-meter extension hose for remote sampling.

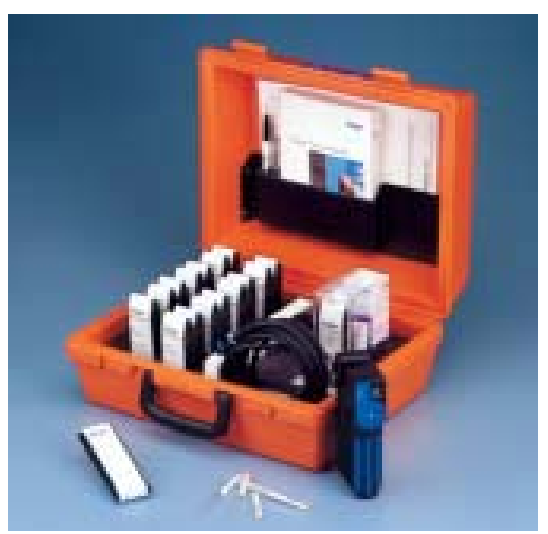

Photo courtesy of Draeger Safety, Inc. (draeger.com)

Figure 9. HazMat Kit, manufactured by Draeger Safety, Inc.

\subsubsection{Heinz 5-Step ${ }^{T M}$ Field Identification Method}

The Heinz 5-Step ${ }^{\text {TM }}$ Field Identification Method is similar to the HazCat ${ }^{\circledR}$ Kit and contains step-bystep instructions, laminated flow charts, and the necessary reagents to perform tests in the field. The fieldtest kit is used to help identify unknown solid and liquid chemicals. It guides users through a series of analyses to help identify explosives, flammable and combustible liquids, flammable solids, oxidizers, corrosives, cyanides and sulfides in ionic compounds, and chlorinated hydrocarbons. The Heinz 5-Step ${ }^{\mathrm{TM}}$ kit was designed to help first responders determine the physical properties of solids, such as thermal stability, water behavior, and $\mathrm{pH}$, and assist in identifying unknown liquids by determining the volatility or explosion hazard potential; if the liquid is an oxidizer, corrosive, or a reducing agent; and the water behavior and reactivity. 


\section{SURVEY DESIGN}

Questions for this survey were designed to acquire direct experience from first responders about colorimetric technology. Prior to developing the survey questions, INL personnel met with three local HazMat teams and used their input on chemical detectors to write a set of targeted questions for use in this survey. The questions were intentionally designed to initiate a straightforward dialogue with the interviewee. A mix of question types, such as yes/no, rating, and open-ended questions, were developed; multiple-choice questions were not asked in this survey. Demographic information was based on the geographic location and population of the cities interviewed.

The initial questions posed to the HazMat professionals related to identifying the first instrumentation they would use for detecting an unknown when approaching a HazMat situation. The HazMat professionals were then asked technical questions about each instrument or detector. The survey included specific questions about the first responder's experience with colorimetric technology. HazMat professionals were also asked to provide their perspective on how well colorimetric methods met their first-response needs and detail any shortcomings they may have encountered. Other questions were about the way first responders used their equipment at the incident scene, which helped us to define how first responders deal with false readings from the instrumentation. Additionally, we asked questions about how detector purchase decisions were made during the procurement process to get feedback in this area. At the end of the survey, we inquired about maintenance and training issues. In order to obtain candid information, the names of the cities and individuals contacted are kept anonymous. A summary of the responses that pertain to the use colorimetric detection methods is listed in Section 5 of this report. 


\section{SELECTION OF CITIES FOR INTERVIEWS}

The goal of this study was to obtain representative information about the use of colorimetric detection methods from across the U.S. Although it is not a statistically representative sample, 14 HazMat teams from small, medium, and large metropolitan areas from the eastern, central, and western regions of the U.S. were selected. The western region included Pacific and Mountain time zones, the central region represented the Central time zone, and the eastern region included the Eastern Time zone. Within each region, four or five cities were selected based on the following population sizes: (1) less than $100 \mathrm{~K},(2)$ from $100 \mathrm{~K}$ to $500 \mathrm{~K}$, (3) from $500 \mathrm{~K}$ to $1,000 \mathrm{~K}$, and (4) greater than $1,000 \mathrm{~K}$.

After cities were selected, official letters were e-mailed to their fire chiefs inviting them to participate in the survey. If no reply was received, a follow-up phone call was initiated to confirm the invitation. If the organization declined this invitation, an alternate city was chosen in the representative region. The Fire Chief was asked to respond to the e-mail and inform us of the appropriate HazMat technician to contact so that we could obtain information about their use of colorimetric detection instruments. An INL staff member then contacted the individual to arrange a time to complete the list of questions. All interviews were conducted over the telephone. Upon contacting the HazMat team member, he or she received a brief introduction explaining the purpose of the survey and was notified that responses would remain anonymous. Responses were recorded in writing and then checked for consistency. The responses were e-mailed to the individual participating in the interview for review. Upon verifying the responses, data analysis began. A typical survey lasted about 30 minutes. 


\section{SUMMARY OF INTERVIEW RESPONSES FROM HAZMAT PROFESSIONALS}

\subsection{Chemical Detection Equipment}

First responders indicated that the deciding factor in choosing an instrument for the scene is situation dependent. When asked which detection method they used initially when arriving on a scene, most responders specified that they used multi-gas meters/photoionization detectors, radiation meters, $\mathrm{pH}$ paper, colorimetric tubes and chips, and chemical agent detectors. Other detectors mentioned were the HazCat ${ }^{\mathbb{B}}$ Kit, HazMat Kit, combustible gas meter, and APD-2000. Figure 10 shows the distribution of the initial type of detection equipment used in the field by first responders to detect an unknown.

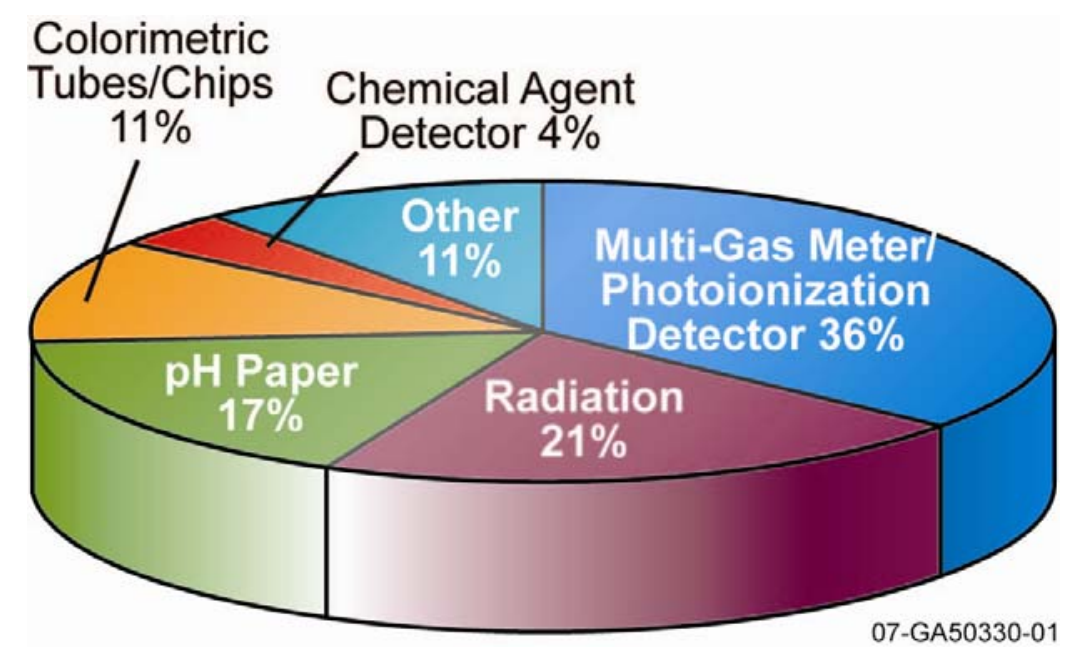

Figure 10. Detection equipment used initially in the field.

The instruments initially used in the field are chosen to assess the situation and determine the type of threat present. The most common interview response of why certain instruments were chosen was to "rule out the possibilities." Simpler, inexpensive instruments are often used prior to using more sophisticated instruments. For example, one responder indicated that " $\mathrm{pH}$ paper is used prior to using a four-gas meter, because if the gas meter was used in an acidic environment the sensors would burnout." Smaller cities noted that funding issues determined what instruments they had available for use. Regardless of the population, HazMat professionals followed an incident-dependent methodology when detecting unknowns in the field. 
Figure 11 shows the percentage of the total number of chemical detection technologies owned by each HazMat team based on size of city. Radiation and biological capabilities are not included in the following graphs, and no claim is made that all chemical detection instruments from each population are represented. Colorimetric technology accounted for nearly $50 \%$ of the total number of chemical detection methods in each population.

\section{a. $<100 \mathrm{~K}$}

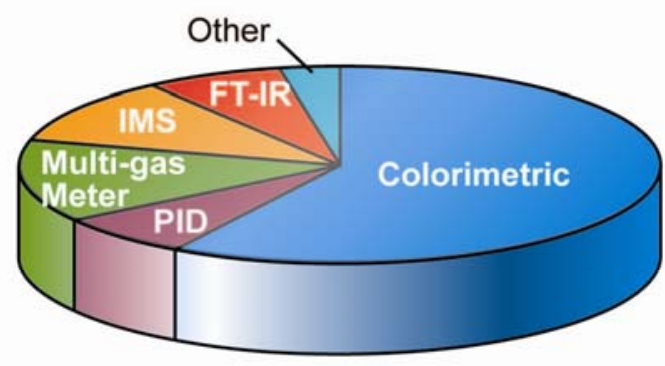

c. $>500 \mathrm{~K}<1,000 \mathrm{~K}$

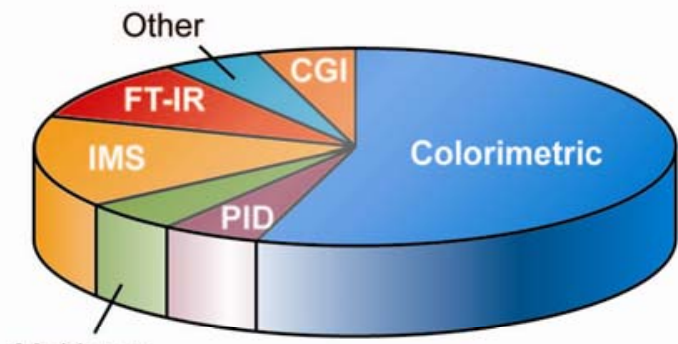

Multi-gas

Meter

\section{b. $>100 \mathrm{~K}<500 \mathrm{~K}$}

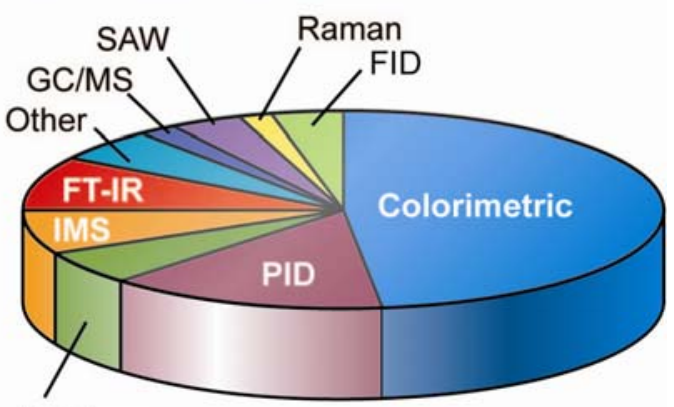

Multi-gas

Meter

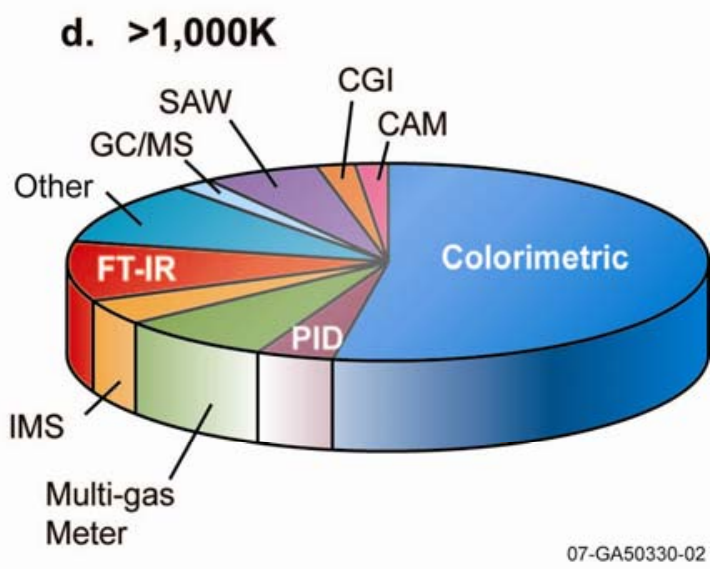

\section{PID=Photoionization Detector IMS=Ion Mobility Spectrometer FT-IR=Fourier Transform Infrared GC/MS=Gas Chromatography/Mass Spectrometry}

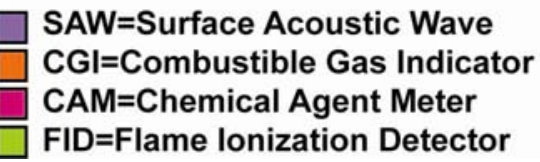

Figure 11. Total chemical detection technologies owned, based on size of city.

Regardless of the size, each population had a multi-gas meter, photoionization detectors, colorimetric methods, chemical weapons kit, ion mobility spectrometry, and infrared technologies available. Some smaller cities did not have direct instrument capability but could obtain instrumentation through a nearby regional HazMat team. Nationwide, the most common colorimetric methods were $\mathrm{pH}$ paper, M8/M9 papers, the HazCat ${ }^{\circledR}$ Kit, the M256A1 Chemical Agent Detector kit, colorimetric tubes and chips, the HazMat Smart-Strip ${ }^{\mathrm{TM}}$, Chemical and Wastewater Classifier Strips, the Chameleon ${ }^{\circledR}$, the HazMat kit, and the Heinz 5-step ${ }^{\mathrm{TM}}$ field identification kit. Compared to the larger populations, the smaller populations did not have as many of the more sophisticated instruments, such as the surface acoustic wave (SAW) technology or gas chromatography/mass spectrometry (GC/MS) technology. 
As a percentage of the total equipment carried, colorimetric methods are the most numerous.

The most common color changing methods and how they were used by HazMat teams was assessed and the results are shown in Table 1.

Table 1. Use of colorimetric detection technology by first responders.

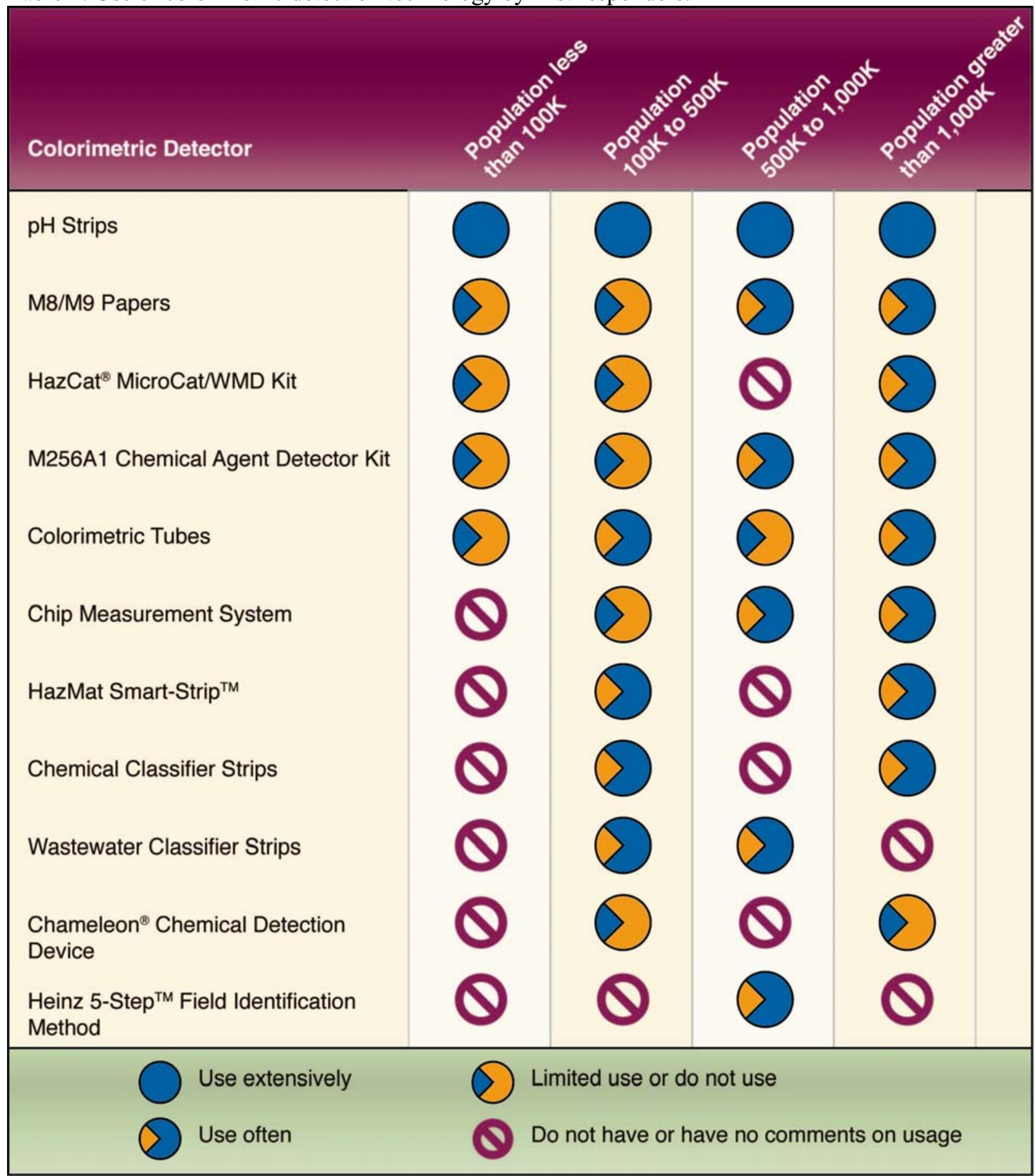

07-GA50330-10 
Specific uses for colorimetric tubes, $\mathrm{pH}$ papers, and M8/M9 papers follow. Overall, 12 of the 14 cities interviewed had colorimetric tubes. The two cities without the tubes included a small western city and a large western city. In general, populations less than $100 \mathrm{~K}$ had colorimetric tubes but only used them in drills and training. The cities with populations from $100 \mathrm{~K}$ to $500 \mathrm{~K}$ had colorimetric tubes and indicated they use them for the following reasons:

- They are "easy to read, interpret, and handle"

- They are used as a "confirmation tool"

- They are used as "one of the main techniques for secondary identification."

This population indicated that they may not use the colorimetric tubes for the following reasons:

- They have a "shelf life"

- $\quad$ They are "complicated."

The cities with populations from $500 \mathrm{~K}$ to $1,000 \mathrm{~K}$ have colorimetric tubes but use them on a limited basis for the following reasons:

- They are "hard to maintain"

- They are "frustrating"

- They are "costly"

- There are "shelf-life concerns"

- $\quad$ The Chip Measurement System is used instead.

The cities with populations greater than $1,000 \mathrm{~K}$ have colorimetric tubes and use them for the following reasons:

- They "verify the presence of a chemical"

- They are used for "specific detection."

One city with a population greater than $1,000 \mathrm{~K}$ has reduced the use of the tubes because:

- The tubes have an accuracy of " $+/-25 \%$ "

- The tubes "give only a 'yes' or 'no' answer."

- The tubes are "complicated"

- They are "costly"

- There are "shelf-life concerns"

- A more specific gas meter is used instead. 
In general, HazMat teams were confused about the capabilities of gas detection tubes. A major metropolitan city stated that they "have not learned the correction factors for temperature and humidity." Cities that use colorimetric tubes do so for detecting the presence of a chemical but do not use the tubes to quantify the chemical. One city stated they use the tubes to identify gases that a photoionization detector (PID) cannot detect.

Every HazMat team uses $\mathrm{pH}$ paper regardless of their city's population, although the type of $\mathrm{pH}$ paper used did vary. Some locations use $\mathrm{pH}$ strips with multiple colors to more exactly determine the $\mathrm{pH}$ value, while others use test strips containing multiple tests on one strip. A few groups use a $\mathrm{pH}$ stick, and others have $\mathrm{pH}$ meters. $\mathrm{pH}$ paper is also included in the HazCat ${ }^{\mathbb{B}}$ Kit used by many HazMat teams. Some groups tape the $\mathrm{pH}$ paper to their suits or meters prior to entering the scene, and other teams throw the $\mathrm{pH}$ strip into the spill upwind. $\mathrm{pH}$ paper is used as a universal indicator for identifying if the spill is an acid or base. The indicator paper is used initially with solid and liquid spills for detecting unknowns, either as a step process in a kit or to determine the scope of the scene. Additionally, $\mathrm{pH}$ paper provides a starting point to help identify the unknown. It is used to determine the type of environment the HazMat technicians are approaching and is an inexpensive method to protect more sophisticated equipment.

Almost all the HazMat teams had M8/M9 papers available and have used them for training purposes. Most of the teams have not had the opportunity to use the papers in an actual incident. HazMat professionals provided the following reasons they use M8/M9 papers:

- To "detect weapons of mass destruction"

- To "detect nerve agent"

- To detect "any possible chemical threat"

- To "rule out the possibilities"

- To "confirm results from other instruments"

- For "training purposes"

- "For an additional safety measure, not as the primary detector."

The main reason HazMat teams do not use M8/M9 papers is because there has not been an opportunity and because the papers have interferences and cross-sensitivities to other products.

\subsection{Colorimetric Instrumentation}

\subsubsection{Detection Method Shortcomings}

HazMat professionals listed various shortcomings on color-changing detection methods. The list of shortcomings for colorimetric methods is outlined in Table 2. 
Table 2. List of shortcomings of colorimetric technology as identified by HazMat professionals.

\begin{tabular}{|c|c|c|}
\hline \multicolumn{3}{|c|}{ List of Shortcomings for Colorimetric Methods } \\
\hline Colorimetric Method & Shortcomings & Population \\
\hline pH paper & $\begin{array}{l}\text { "Prone to subjective readings" } \\
\text { "Smaller pH strips are difficult to view" } \\
\text { "Hard to view color changes in the dark" } \\
\text { "Older paper discolors" } \\
\text { "Colors don't stay fast, and may bleed over time" } \\
\text { "Hard to remove from the container" }\end{array}$ & $\begin{array}{l}<100 \mathrm{~K} \\
<100 \mathrm{~K} \\
100 \mathrm{~K} \text { to } 500 \mathrm{~K} \\
100 \mathrm{~K} \text { to } 500 \mathrm{~K} \\
100 \mathrm{~K} \text { to } 500 \mathrm{~K} \\
>1,000 \mathrm{~K}\end{array}$ \\
\hline M8 & "False positives" & $500 \mathrm{~K}$ to $1,000 \mathrm{~K}$ \\
\hline $\mathrm{HazCat}^{\circledR} \mathrm{Kit}$ & $\begin{array}{l}\text { "Hard to use when suited up" } \\
\text { "One individual may see a color change } \\
\text { differently than another" } \\
\text { "Difficult to use because of the multiple steps } \\
\text { needed to complete an analysis" } \\
\text { "Human error can alter the results" } \\
\text { "Interpretation of the color changes is } \\
\text { dependent on user" } \\
\text { "Reagents in kit need to be constantly replaced" }\end{array}$ & $\begin{array}{l}<100 \mathrm{~K} \\
100 \mathrm{~K} \text { to } 500 \mathrm{~K} \\
100 \mathrm{~K} \text { to } 500 \mathrm{~K} \\
100 \mathrm{~K} \text { to } 500 \mathrm{~K} \\
>1,000 \mathrm{~K} \\
>1,000 \mathrm{~K}\end{array}$ \\
\hline Colorimetric tubes & $\begin{array}{l}\text { "There are multiple interferences or reactions } \\
\text { that could change the concentration" } \\
\text { "The directions need to be read everytime" } \\
\text { "Time consuming" } \\
\text { "Costly to replace" } \\
\text { "Expiration dates present problems" } \\
\text { "Chemical substance must be known" } \\
\text { "The number of pulls on the pump is inconsistent" } \\
\text { "Target chemical needs to be known" } \\
\text { "Pump draws are not standardized" }\end{array}$ & $\begin{array}{l}<100 \mathrm{~K} \\
<100 \mathrm{~K} \\
<100 \mathrm{~K} \\
<100 \mathrm{~K} \\
<100 \mathrm{~K} \\
<100 \mathrm{~K} \\
100 \mathrm{~K} \text { to } 500 \mathrm{~K} \\
100 \mathrm{~K} \text { to } 500 \mathrm{~K} \\
500 \mathrm{~K} \text { to } 1,000 \mathrm{~K}\end{array}$ \\
\hline
\end{tabular}


Table 2. (continued).

\begin{tabular}{|c|c|c|}
\hline \multicolumn{3}{|c|}{ List of Shortcomings for Colorimetric Methods (cont'd) } \\
\hline Colorimetric Method & Shortcomings & Population \\
\hline $\begin{array}{l}\text { Colorimetric tubes } \\
\text { (cont'd) }\end{array}$ & $\begin{array}{l}\text { "Highly inaccurate" } \\
\text { "Difficult to use in humid and cold environments" } \\
\text { "The instructions are difficult to follow" } \\
\text { "Narrow and very specific for chemical" } \\
\text { "Labor intensive" } \\
\text { Have an accuracy of "+l-25\%" } \\
\text { "Not every one notes the same color change" } \\
\text { "The results are not easily read" } \\
\text { "The labels on the tubes are too small" } \\
\text { "Hard to see the markings in the dark" } \\
\text { "Cross-contamination issues" } \\
\text { "False positives" } \\
\text { "Difficult to calculate conversion factors } \\
\text { for temperature and humidity" }\end{array}$ & $\begin{array}{l}>1,000 \mathrm{~K} \\
>1,000 \mathrm{~K} \\
>1,000 \mathrm{~K} \\
>1,000 \mathrm{~K} \\
>1,000 \mathrm{~K} \\
>1,000 \mathrm{~K} \\
>1,000 \mathrm{~K} \\
>1,000 \mathrm{~K} \\
>1,000 \mathrm{~K} \\
>1,000 \mathrm{~K} \\
>1,000 \mathrm{~K} \\
>1,000 \mathrm{~K} \\
>1,000 \mathrm{~K}\end{array}$ \\
\hline $\begin{array}{l}\text { Chip Measurement } \\
\text { System (CMS) }\end{array}$ & "Hard to see the color changes" & $>1,000 \mathrm{~K}$ \\
\hline HazMat Smart-Strip ${ }^{\top M}$ & $\begin{array}{l}\text { "Lose reagent if they are not sealed" } \\
\text { "Operator must be aware of the expected } \\
\text { color changes" }\end{array}$ & $\begin{array}{l}>1,000 \mathrm{~K} \\
>1,000 \mathrm{~K}\end{array}$ \\
\hline Chameleon $^{\circledast}$ & $\begin{array}{l}\text { "Rarely available" } \\
\text { "Prone to false positives and negatives" } \\
\text { "Interferes with the first responder's handwork" } \\
\text { "Doesn't give information until you are } \\
\text { already in a situation" }\end{array}$ & $\begin{array}{l}100 \mathrm{~K} \text { to } 500 \mathrm{~K} \\
>1,000 \mathrm{~K} \\
>1,000 \mathrm{~K} \\
>1,000 \mathrm{~K}\end{array}$ \\
\hline
\end{tabular}

07-GA50330-12 
When asked about colorimetric shortcomings, three responses from major fire departments addressed the issue of weather or ambient air conditions:

- $\quad$ From a large $(>1,000 \mathrm{~K})$ central zone city, "Draeger tubes have some problems with the chemistry and are humidity dependent. They cannot be used when it is raining or when it is really humid. Also cannot be used if they are too cold."

- $\quad$ From a large $(>1,000 \mathrm{~K})$ eastern city, "weather" was listed as a cause of variability in colorimetric detector performance.

- $\quad$ From an intermediate-sized central zone city ( $100 \mathrm{~K}$ to $500 \mathrm{~K})$, humidity was mentioned as a variable that must be taken into account by the first responders.

Inconsistencies in colorimetric detector responses with changing weather are an additional complication for first responders using these devices. Personnel must also cope with trying to observe color changes in poor light and the need to count pump strokes in a noisy, chaotic environment that may be smoky and flooded with water. As a consequence, several of the departments use the tubes only to determine what chemicals are present and not for measuring concentrations.

The reluctance to use the tubes for quantifying chemicals may be caused by a lack of training with the devices, inherent detector limitations, or both. Even major departments admit to limitations in their knowledge of how to use colorimetric tubes. The following response is from a representative of a large $(>1,000 \mathrm{~K})$ central zone fire department who was asked about their team's experience with colorimetric detectors:

- $\quad$ Referring to Draeger tubes: "Most members of the HazMat team use them only as an indicator of the presence not as a qualitative (sic) measurement since most of the HazMat team has not learned how to do the corrective factors for temperature and pressure."

Concerns voiced at some departments about the accuracy of colorimetric methods for measuring chemical concentrations may also be related to a lack of familiarity and training. A large $(>1,000 \mathrm{~K})$ western region department indicated:

- "Colorimetric tubes can be labor intensive and [have an accuracy of] +/- of 25\%."

In fact, measurements at this level of accuracy might well be useful in some situations.

Other respondents described the deficiencies of colorimetric detectors with wildly divergent descriptions:

- $\quad$ "None. They are all easy to handle, simple to read, have a chart available, and easy-to-see color changes."

- "Highly inaccurate; they are only good for chemical family."

It seems likely that training, experience, the products used, and local weather conditions all play a role in the perception that first responders have regarding the usefulness of colorimetric detectors. 


\subsubsection{Overcoming Some of the Shortcomings of Colorimetric Detection Equipment}

Many HazMat professionals gave suggestions on how to overcome some of the shortcomings of colorimetric methods. Table 3 provides suggested tips first responders use when handling colorimetric detection equipment.

Table 3. Tips for using colorimetric methods.

\begin{tabular}{|l|l|}
\hline \multicolumn{1}{|c|}{ Tips for Using Colorimetric Methods } \\
\hline Method & \multicolumn{1}{c|}{ Suggested Tips } \\
\hline pH paper & $\begin{array}{l}\text { "Attach pH paper to a stick and use as a lead" } \\
\text { "Use pH paper prior to using multiple gas meter otherwise sensors burn out" } \\
\text { "Wear pH paper on our suits" } \\
\text { "Use clothes pins to remove pH paper from small containers" } \\
\text { "Tape pH paper to atmosphere meter" } \\
\text { "Wet pH paper first if testing dry solids" } \\
\text { "Use jumbo strips" (9 1/2 in. } x \text { 1 in.) } \\
\text { "Throw pH paper into a spill upwind" } \\
\text { "Sample pH on opposite sides of a spill" } \\
\text { "When suited up, hold pH paper up to Entry Cam, so personnel outside } \\
\text { the zone can make determination" }\end{array}$ \\
\hline M8/M9 Papers & $\begin{array}{l}\text { "Apply M8/M9 papers to suits at ankle, knee, or shoulder so they are } \\
\text { easy to grab" }\end{array}$ \\
\hline Colorimetric tubes & $\begin{array}{l}\text { "Use a radio to communicate the number of pump strokes to the } \\
\text { individual inside/outside the zone" }\end{array}$ \\
\hline
\end{tabular}

07-GA50330-13

HazMat professionals were asked if colorimetric methods provided the data that they needed to classify, identify, and quantify chemicals during a response action. Their reply was mostly favorable, with some exceptions listed below. In populations less than $100 \mathrm{~K}$ the responses were positive that colorimetric methods provided the data needed to make field decisions, if they were careful to match the right method with the right decision. Responders understood that the HazCat ${ }^{\mathbb{R}}$ Kit only classifies a chemical and Draeger tubes are used for detecting a known specific chemical. They were, however, confused about the ability of Draeger tubes to quantify a chemical. Other technologies were often used to identify and quantify a specific chemical. Populations $100 \mathrm{~K}$ to $500 \mathrm{~K}$ indicated that colorimetric detection methods did provide the data needed for classification and identification but that the methods did not have a broad enough concentration range. Populations $500 \mathrm{~K}$ to $1,000 \mathrm{~K}$ showed mixed responses with regard to colorimetric methods. Responses ranged from a strong "Yes" to "No, they are not useful." Populations greater than $1,000 \mathrm{~K}$ were favorable that colorimetric detection provided the necessary data to make field decisions. Even so, for all groups, colorimetric methods are not relied upon as the only source of 
detection. All populations indicated that other technologies are used to confirm the colorimetric determinations.

Despite the numerous shortcomings identified by responders, colorimetric technology was rated as above average by first responders in every region of the U.S. Figure 12 shows how colorimetric technology was rated on a scale from 1 to 5 based on geographical region. Error bars show the standard deviation based on the n-1 method.

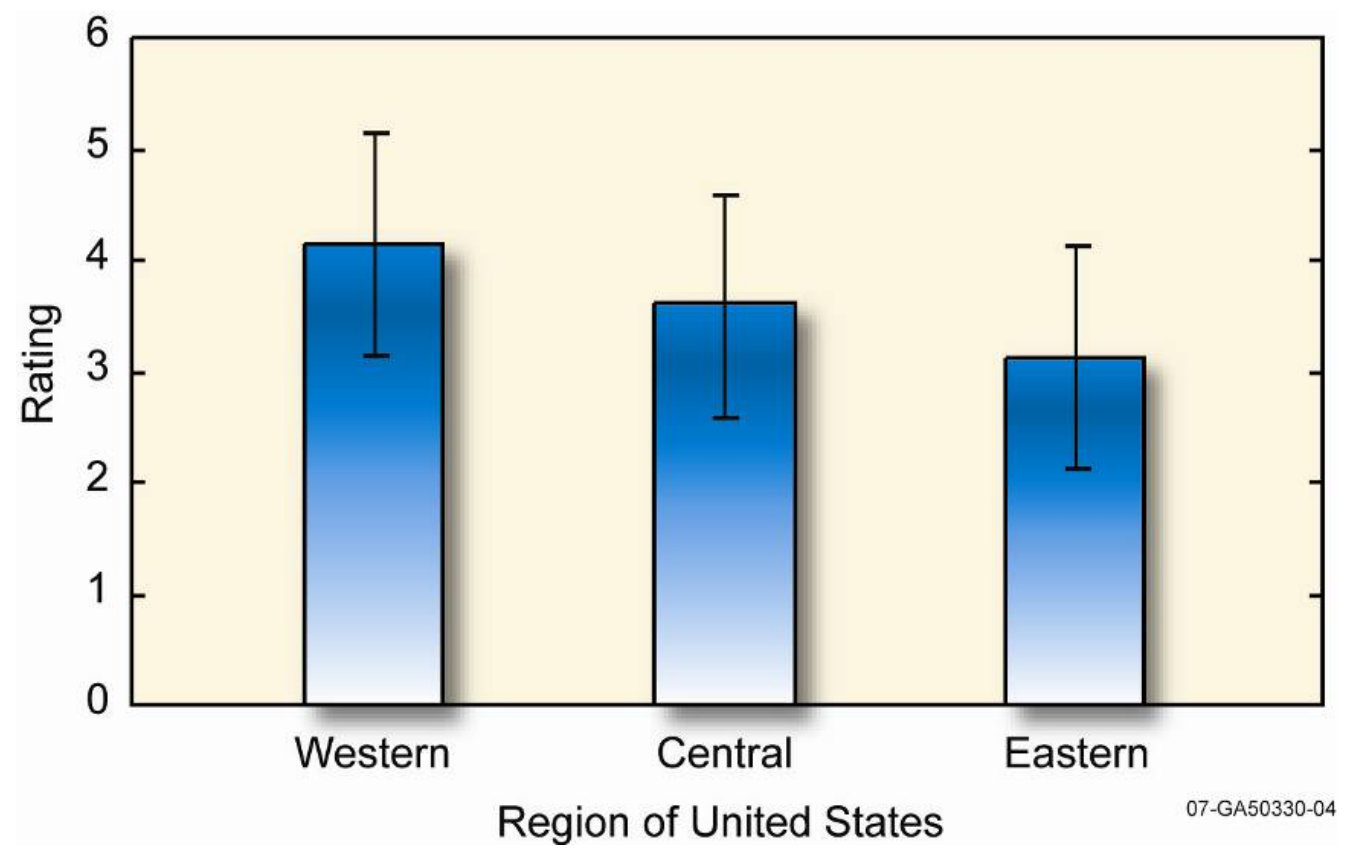

Figure 12. Colorimetric detector rating ( 1 is low, 5 is high) based on geographic region.

\subsection{Incident Scene Information}

For cities of all sizes, secondary confirmations are conducted to reduce or eliminate the possibilities of a false positive or false negative. HazMat professionals indicated that they repeated the test using a different technology or different method, used the same method, confirmed results with the physiological response, or used an independent laboratory to confirm results. Figure 13 shows how HazMat professionals handled false positives or negatives. Across the nation, it is standard to confirm results using another chemical detection method or an instrument employing a different technology. No team relied on just one detection method or had confidence in one chemical detection method over another, and the results were always checked using multiple methods. They always confirm the readings to ensure that any shortcomings of the instrument do not negatively influence the response to the scenario. Using two different technologies provides a backup and ensures accuracy. 


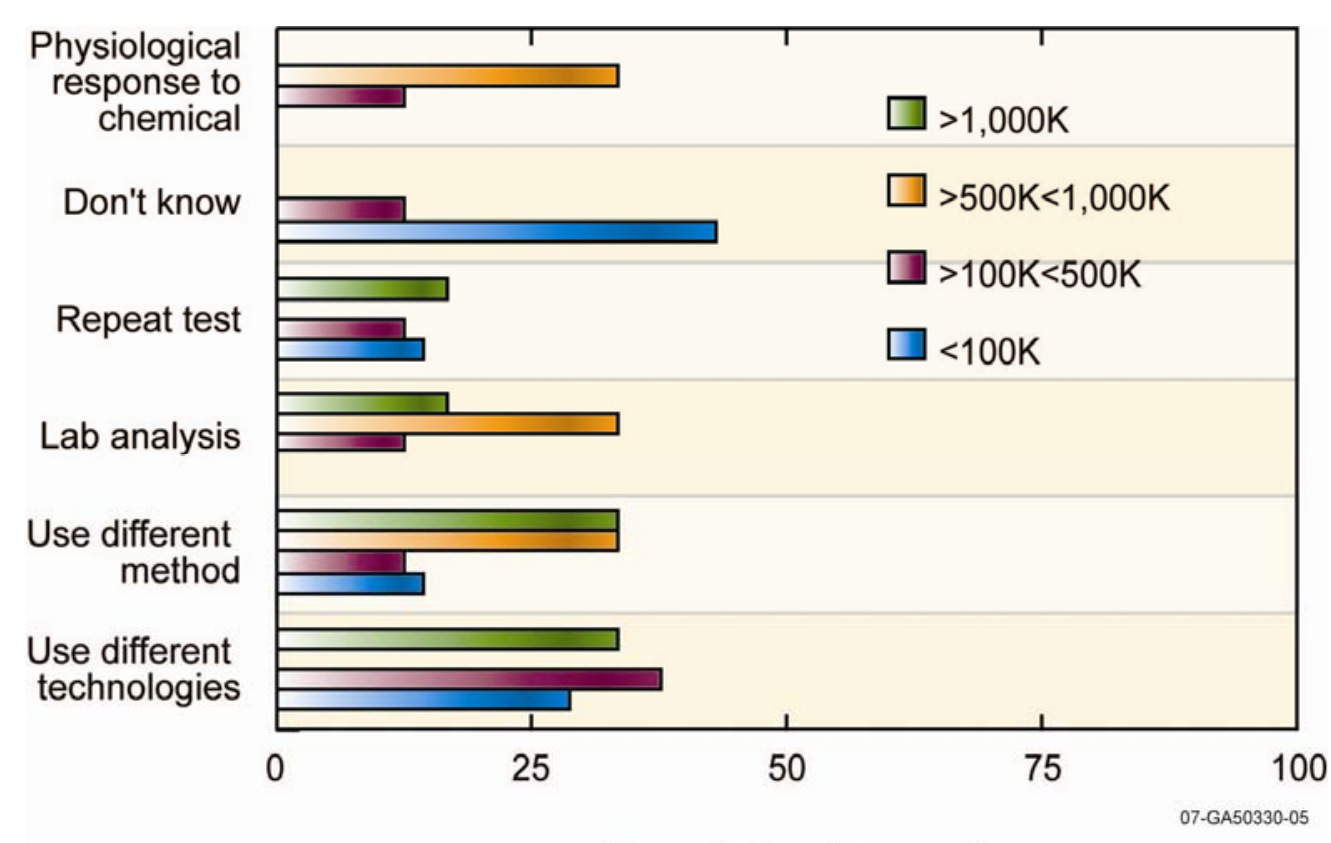

Percentage of responders

Figure 13. Distribution of how first responders dealt with a false positive or negative.

In the smaller populations, the ability to run multiple tests was limited by manpower. Overall, one method was not used as the sole source of product identification. Other types of identification besides chemical detection instruments are used when determining the type of threat present at an incident. The HazMat technicians confirmed instrument responses with the location of the incident, personnel in the area, physiological response, and personal experience. Most regions have the ability to collect a sample and send it to an onsite support laboratory or a state/federal analytical laboratory.

\subsection{Decision Making Information}

In general, all the HazMat teams have an informal network within their local city and with neighboring county fire departments. The smaller populations coordinate with the state and some cities are supported by a regional support team. The larger populations have the ability to network with a larger metropolitan area and coordinate activities on a larger scale. There are also federal networking groups.

Larger populations make instrument selection decisions through committee meetings made up of first responders, and the committee decisions are usually made by mutual consensus. Smaller populations rely on specific individuals or the state for equipment decisions. Nationwide, instrumentation is recommended for purchase based on individual research, or vendor input, but smaller populations indicated that they "use what the State provides" through the grant system, unlike larger populations that generally have additional resources to supplement chemical detection instrumentation. Some teams mentioned they like to use the equipment on a trial basis prior to making a purchase.

Generally, all HazMat teams have the flexibility to select instruments based on their individual needs. Smaller cities are more dependent on the available equipment lists, and the individual teams have some ability to select the instruments based on their needs. Every population has a budget that forces them to make choices in selection of their equipment. Figure 14 shows the distribution, based on the U. S. region, of who is responsible for selecting chemical detection instrumentation. Figure 15 represents the same information, sorting the responses based on population. 


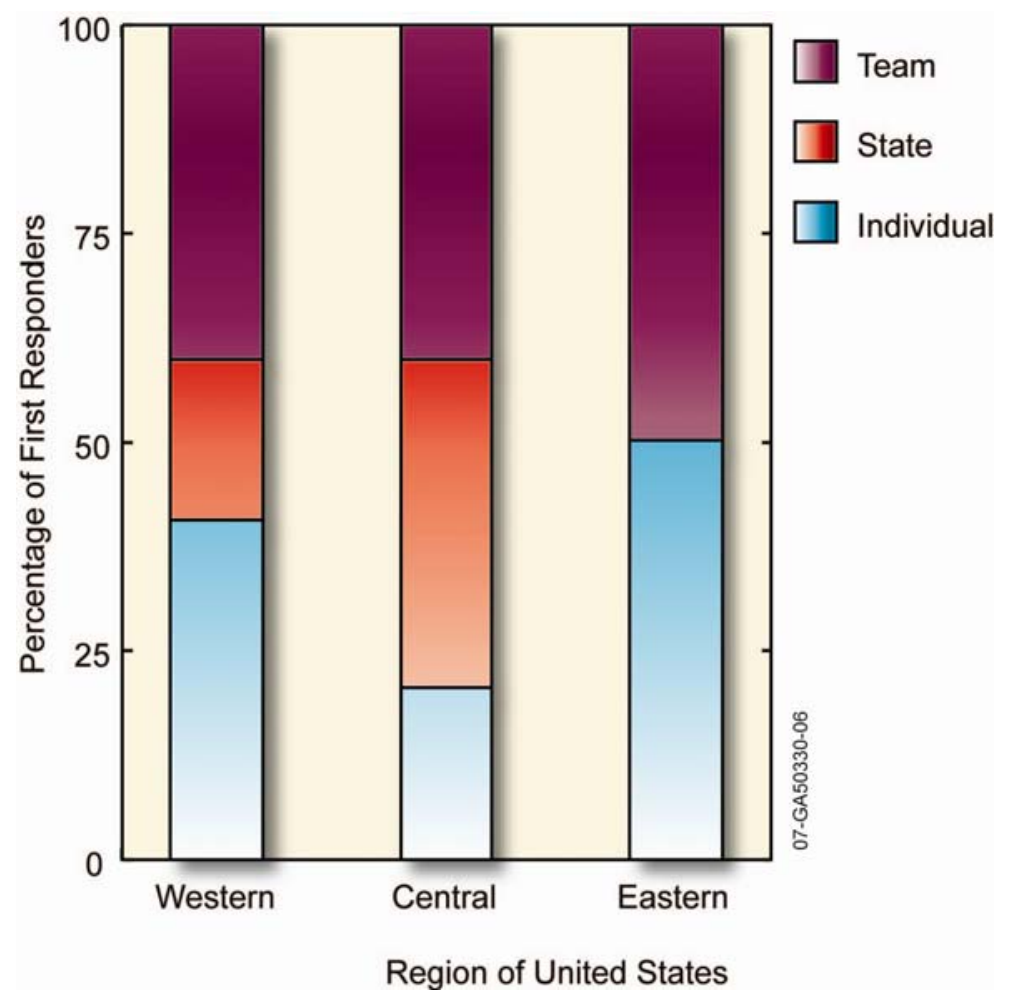

Figure 14. Percentage of first responders responsible for selecting instruments, based on region.

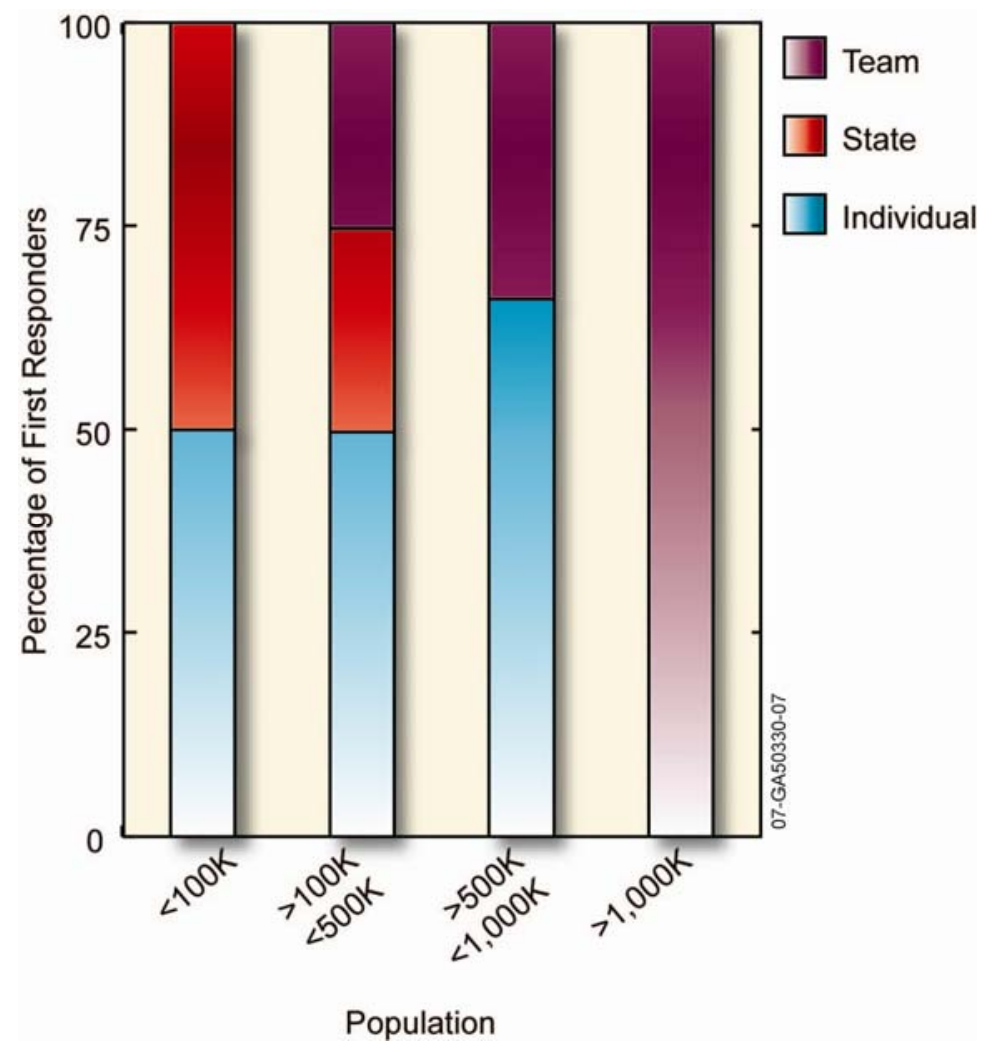

Figure 15. Percentage of first responders responsible for selecting instruments, based on population. 


\subsection{Maintenance and Training}

Figure 16 shows the distribution of how chemical detector training for HazMat professionals is completed. In most cases, training is offered within the department; however, some manufactures provide training when the instrument is purchased, or training is provided on a state level. Occasionally, the teams have sent individuals to conferences or specialized training courses. The teams have a train-the-trainer system as well.

a. $<100 \mathrm{~K}$

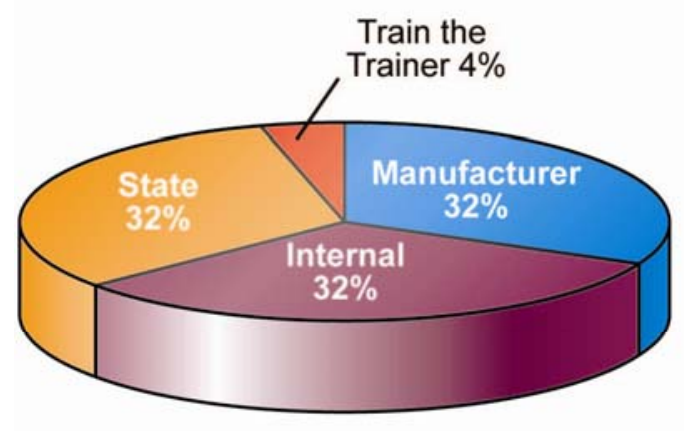

c. $>500 \mathrm{~K}<1,000 \mathrm{~K}$

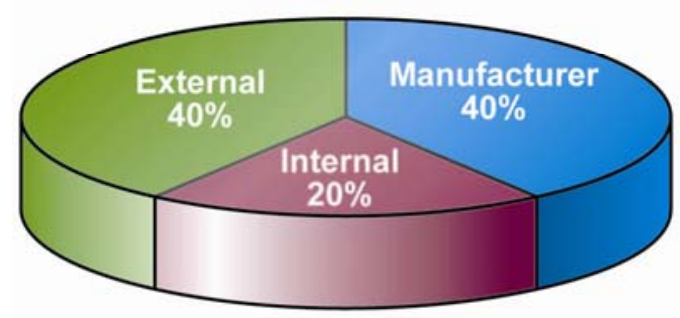

b. $>100 \mathrm{~K}<500 \mathrm{~K}$

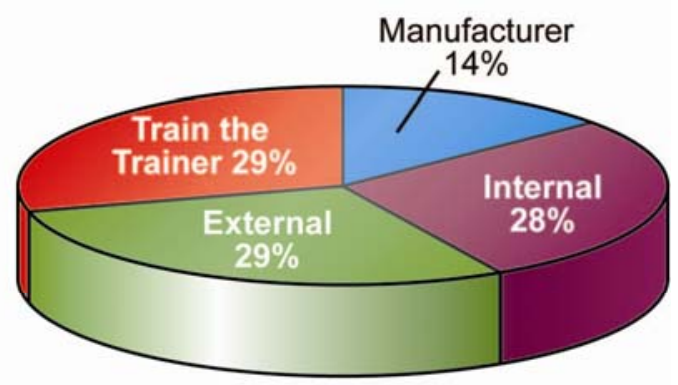

d. $>1,000 \mathrm{~K}$

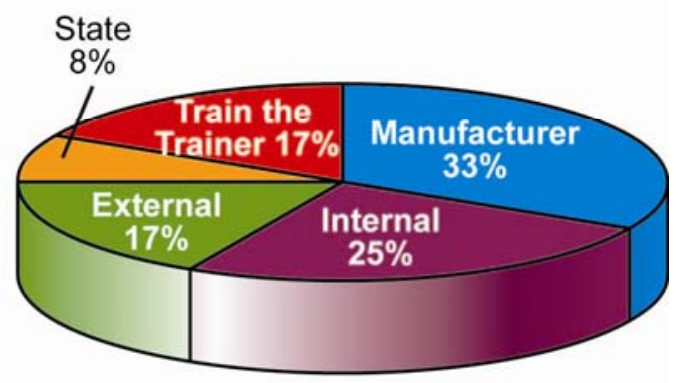

\section{State $\quad \square$ Train the Trainer \\ 07-GA50330-08 \\ Manufacturer \\ Internal \\ External}

pulation. 
Figure 17 shows the percentage of responders whose personal experience matched the manufacturer-provided literature. Sixty percent of the HazMat technicians indicated that their experience matched manufacturer data, compared to $30 \%$ of the first responders who indicated that manufacture data did not match their experience. First responders indicated that false claims, instrument trouble, and salesman experience presented problems. Additionally, first responders made comments that the emergency response is not a controlled environment, as is often portrayed by the literature.

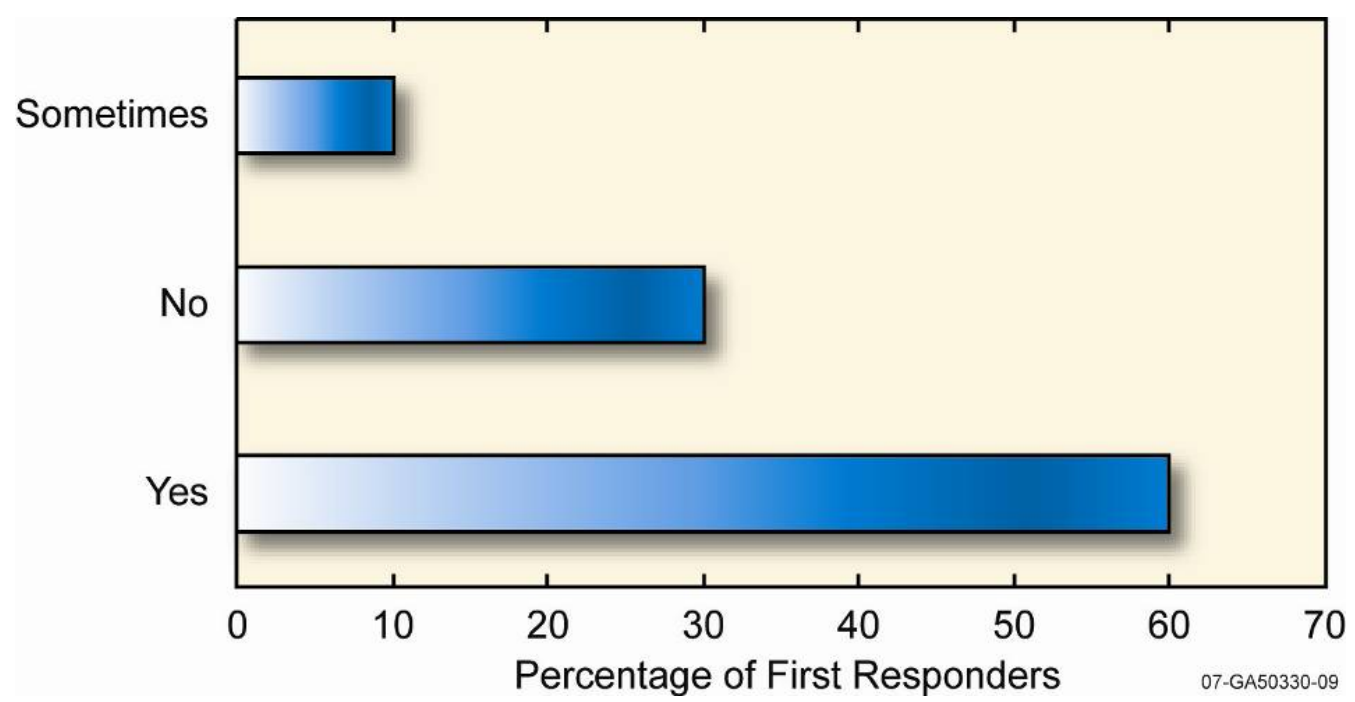

Figure 17. Percentage of responders who thought the manufacturers' data was realistic. 


\section{CONCLUSIONS AND PROPOSED NEXT STEPS}

When responding to an incident, HazMat response teams need accurate information to assess hazards, evaluate the level of risk, and make critical decisions. Chemical detection instruments are tools used by first responders to help determine the nature and magnitude of the chemical threat to the emergency response teams, the public, and the environment. In this report, information about chemical detection methods, specifically colorimetric technology, was gathered, and user information was collected from HazMat professionals. Response teams explained how equipment decisions are made, shared their experience using colorimetric chemical detection methods, and provided their perspectives on how well these instruments met their first response needs. The following findings were identified:

1. Colorimetric technologies are valued by the first responder because they are inexpensive, simple to use, and can aid in determining the extent of a potential threat.

2. In all the populations surveyed, colorimetric technologies account for nearly $50 \%$ of the total number of chemical detection methods HazMat professionals own.

3. There are over 50 colorimetric detection methods available on the market, yet of the populations surveyed, only 12 colorimetric methods were identified as being used by their HazMat professionals.

4. Colorimetric methods are seldom used as part of an integrated system for detecting and identifying chemicals. Instead, they are often used independently or as a simple confirmatory analysis.

5. Although the deciding factor in choosing an instrument for the incident scene is situation dependent, commonly used instruments like radiation meters, multiple gas meters, photoionization detectors, and $\mathrm{pH}$ paper were the initial types of detectors used at an incident.

6. HazMat teams are confused about the capabilities of gas detection tubes, with even major metropolitan areas having difficulty correcting for temperature and humidity. One larger city uses a newer electronic chip technology, which is more quantitative and may be replacing the tubes.

7. Most HazMat professionals use colorimetric tubes for qualitative analysis, not for quantification.

8. $\mathrm{pH}$ paper is universally used as an initial indicator by HazMat professionals because classifying unknown chemicals as acidic or basic is an important initial consideration.

9. All cities interviewed use a follow-up detection method to confirm results when analyzing an unknown at an incident scene.

\subsection{Conclusions}

Given these findings, it appears that some colorimetric detectors are not used to their full potential. Use of paper detectors appears well founded. However, additional information can be obtained from detection tubes by integrating their use into a systematic approach to HazMat site analysis. Specific recommendations are:

- Increase education on the quantitative aspects of detector tubes.

- Develop a user-decision context for the use of colorimetric methods in the field. Some of the test kits have a rudimentary system for use of colorimetric detectors, but this can be greatly improved. 
- Plan an independent performance evaluation of the integrated system, including colorimetric and other methods.

- Develop challenging test samples to evaluate both the overall system and colorimetric methods in particular.

\subsection{Proposed Next Steps}

- $\quad$ Continue evaluation of other detectors used by first responders, such as hand-held detectors.

- $\quad$ Evaluate the overall system and each of its specific components.

- $\quad$ Provide additional information for first responders to use in their purchase and use of chemical detectors. 


\section{REFERENCES}

Fatah, A. A., et al., 2005, Guide for Selection of Chemical Agent and Toxic Industrial Material Detection Equipment for Emergency First Responders, $2^{\text {nd }}$ Edition, Guide 100-04, Volume I and II. U.S. Department of Homeland Security, March 2005.

Fatah, A. A., et al., 2007, Guide for Selection of Chemical Detection Equipment for Emergency First Responders, 3rd Edition, Guide 100-06, U.S. Department of Homeland Security, January 2007. 
Appendix A

Colorimetric Detection Methods 


\section{Appendix A}

\section{Colorimetric Detection Methods}

Given the widespread availability of colorimetric detection by first responders, an effort was made to identify the available colorimetric detection methods. Colorimetric methods were initially identified in the Responder Knowledge Base (http://www.rkb.mipt.org/lists.cfm) of the National Memorial Institute for the Prevention of Terrorism. This website listed over 40 colorimetric technologies under their 2007 authorized equipment list. The website provides summary information about these instruments and links to the manufacturers' websites. Additional colorimetric detection methods were identified in the National Institutes of Standards and Technology Guide for the Selection of Chemical Agent and Toxic Industrial Material Detection Equipment for First Responders, Volume I and II (Fatah et al., 2005), the Guide for Selection of Chemical Detection Equipment for Emergency First Responders (Fatah et al., 2007), and the Firefighting Resources of California Organized for Potential Emergencies (http://www.firescope.org) HazMat Standard Equipment List. A few additional instruments were subsequently identified through Internet searches. No claim is made that all colorimetric instruments were identified or that identified instruments represent the best quality or type available. Table A-1 lists the colorimetric methods, manufacturers, and web addresses of the items.

Table A-1. 2007 colorimetric detection methods.

\begin{tabular}{|c|c|c|}
\hline Colorimetric Detection & Manufacturer & Web Page \\
\hline $\begin{array}{l}\text { 3-Way Paper, Chemical } \\
\text { Agent Liquid Detector }\end{array}$ & Anachemia Canada, Inc & http://www.anachemia.com \\
\hline $\begin{array}{l}\text { ABC-M8 VGH Chemical } \\
\text { Agent Detector Paper }\end{array}$ & Truetech, Inc. & None Available \\
\hline $\begin{array}{l}\text { Agentase Blister (HD, HN, } \\
\text { AC, CK) Agent Sensor } 5 \\
\text { Pack }\end{array}$ & $\mathrm{ICX}^{\mathrm{TM}}$ Agentase & http://www.agentase.com \\
\hline Agentase CAD Kit & $\mathrm{ICX}^{\mathrm{TM}}$ Agentase & http://www.agentase.com \\
\hline Agentase Nerve Agent Kit & $\mathrm{ICX}^{\mathrm{TM}}$ Agentase & http://www.agentase.com \\
\hline $\begin{array}{l}\text { Chameleon }{ }^{\circledR} \text { Chemical } \\
\text { Detection Device }\end{array}$ & Morphix Technologies $^{\mathrm{TM}}$ & http://www.morphtec.com \\
\hline Arsenic Quick ${ }^{\mathrm{TM}}$ Kit & Industrial Test Systems & http://www.sensafe.com \\
\hline $\begin{array}{l}\text { Arsenic Quick }{ }^{\mathrm{TM}} \text {, Low } \\
\text { Range Kit }\end{array}$ & Industrial Test Systems & http://www.sensafe.com \\
\hline $\begin{array}{l}\text { Chemical Agent Detector C- } \\
2 \text { Kit }\end{array}$ & Anachemia Canada, Inc. & http://www.anachemia.com \\
\hline $\begin{array}{l}\text { Chemkey TLD Toxic Gas } \\
\text { Monitor }\end{array}$ & Honeywell Analytics, Inc. & http://www.honeywellanalytics.com \\
\hline ChromAir Badges & Morphix Technologies ${ }^{\mathrm{TM}}$ & http://www.morphtec.com \\
\hline $\begin{array}{l}\text { Civil Defense Kit (CDK) } \\
\text { Basic 20A }\end{array}$ & Nextteq $^{\circledR}$ & http://www.nextteq.com \\
\hline CM4-P Gas Monitor & Honeywell Analytics, Inc. & http://www.honeywellanalytics.com \\
\hline
\end{tabular}


Table A-1. (continued).

\begin{tabular}{|c|c|c|}
\hline Colorimetric Detection & Manufacturer & Web Page \\
\hline $\begin{array}{l}\text { Draeger Chip Measurement } \\
\text { System (CMS) Analyzer }\end{array}$ & Draeger Safety, Inc. & http://www.draeger.com \\
\hline $\begin{array}{l}\text { Draeger Civil Defense } \\
\text { Simultest (CDS) Kit }\end{array}$ & Draeger Safety, Inc. & http://www.draeger.com \\
\hline $\begin{array}{l}\text { Draeger CMS Emergency } \\
\text { Response Kit }\end{array}$ & Draeger Safety, Inc. & http://www.draeger.com \\
\hline Draeger HazMat Kit & Draeger Safety, Inc. & http://www.draeger.com \\
\hline $\begin{array}{l}\text { Draeger HazMat Simultest } \\
\text { Kit }\end{array}$ & Draeger Safety, Inc. & http://www.draeger.com \\
\hline Hazard Classification Kit & HazChem, LLC & http://www.hazchemllc.com \\
\hline $\begin{array}{l}\mathrm{HazCat}^{\mathbb{B}} \text { Kit, Basic (Model } \\
\text { KT1209) }\end{array}$ & HazTech Systems $^{\mathrm{TM}}$, Inc. & http://www.hazcat.com \\
\hline $\begin{array}{l}\text { HazCat }^{\circledR} \text { MicroCat/WMD } \\
\text { Kit (Model KT1040) }\end{array}$ & HazTech Systems $^{\mathrm{TM}}$, Inc. & http://www.hazcat.com \\
\hline $\begin{array}{l}\mathrm{HazCat}^{\mathbb{B}}{ }^{\text {WMD Kit (Model }} \\
\text { KT 1235) }\end{array}$ & HazTech Systems ${ }^{\mathrm{TM}}$, Inc. & http://www.hazcat.com \\
\hline HazMat Kit, Standard & Nextteq ${ }^{\circledR}$ & http://www.nextteq.com \\
\hline HazMat Smart-Strip ${ }^{\mathrm{TM}}$ & Safety Solutions, Inc. & http://www.smart-strip.com \\
\hline $\begin{array}{l}\text { Heinz } 5 \text {-Step }{ }^{\mathrm{TM}} \text { Field } \\
\text { Identification Kit } 8 \text { Model } \\
2000\end{array}$ & $\begin{array}{l}\text { Heinz Laboratories } \\
\text { International }\end{array}$ & http://www.heinztraining.com/Fieldmethod.htm \\
\hline $\begin{array}{l}\text { Kitagawa Gas Detector } \\
\text { Tubes }\end{array}$ & $\begin{array}{l}\text { Matheson Safety } \\
\text { Products/Matheson Tri Gas }\end{array}$ & http://www.mathesontrigas.com \\
\hline $\begin{array}{l}\text { M18A2 Chemical Agent } \\
\text { Detector Kit }\end{array}$ & Truetech, Inc. & None Available \\
\hline $\begin{array}{l}\text { M256A1 Chemical Agent } \\
\text { Detector Kit }\end{array}$ & Anachemia Canada, Inc. & http://www.anachemia.com \\
\hline M272 Water Kit & Truetech, Inc. & None Available \\
\hline $\begin{array}{l}\text { M8 Chemical Detection } \\
\text { Paper }\end{array}$ & TACOM-SBC & None Available \\
\hline $\begin{array}{l}\text { M9 Chemical Agent } \\
\text { Detector Paper }\end{array}$ & Truetech, Inc. & None Available \\
\hline M9 Chemical Detector Paper & TACOM-SBC & None Available \\
\hline $\begin{array}{l}\text { MSA Detector Tube Kit for } \\
\text { Chemical Warfare Agents }\end{array}$ & $\begin{array}{l}\text { Mine Safety Appliances } \\
\text { (MSA) }\end{array}$ & http://www.msanet.com \\
\hline MSA Gas Detection Tubes & MSA & http://www.msanet.com \\
\hline $\begin{array}{l}\text { Nerve Agent Sensor } 5 \text { pack } \\
\text { ICX }^{\mathrm{TM}} \text { Agentase }\end{array}$ & $\mathrm{ICX}^{\mathrm{TM}}$ Agentase & http://www.agentase.com \\
\hline $\begin{array}{l}\text { Nerve Agent Vapor Detector } \\
\text { (NAVD) }\end{array}$ & Anachemia Canada, Inc. & http://www.anachemia.com \\
\hline Nextstep ${ }^{\circledR}$ Portable Toxic & Scott ${ }^{\mathbb{B}}$ Health \& Safety & http:/www.scottinstruments.com \\
\hline
\end{tabular}


Table A-1. (continued).

\begin{tabular}{|c|c|c|}
\hline Colorimetric Detection & Manufacturer & Web Page \\
\hline \multicolumn{3}{|l|}{ Monitor } \\
\hline No. 1 Mark 1 Detector Kit & $\begin{array}{l}\text { Richmond Packaging (UK) } \\
\text { Limited }\end{array}$ & None Available \\
\hline SafeAir Monitoring System & Morphix Technologies $^{\mathrm{TM}}$ & http://www.morphtec.com \\
\hline $\begin{array}{l}\text { Sensidyne Gas Detection } \\
\text { Tubes }\end{array}$ & Sensidyne, Inc. & http://www.sensidyne.com \\
\hline $\begin{array}{l}\text { Single Point Monitor (SPM) } \\
\text { Toxic Gas Monitor }\end{array}$ & Honeywell Analytics, Inc. & http://www.honeywellanalytics.com \\
\hline Smart 2 Colorimeter & LaMotte Co. & http://www.lamotte.com \\
\hline $\begin{array}{l}\text { Smart M-8 Nerve Agent } \\
\text { Detector }\end{array}$ & Safety Solutions, Inc. & http://www.smart-strip.com \\
\hline Sure Spot Active Sampler & Scott ${ }^{\circledR}$ Health \& Safety & http:/www.scottinstruments.com \\
\hline $\begin{array}{l}\text { Test Strips, Chemical } \\
\text { Classifier Strip }\end{array}$ & Spilfyter ${ }^{\mathbb{R}}$ & http://www.spilfyter.com \\
\hline Test Strips, Chloride & Industrial Test Systems & http://www.sensafe.com \\
\hline Test Strips, Chlorine & Emquant $^{\circledR}$ & http://www.labsafety.com \\
\hline $\begin{array}{l}\text { Test Strips, Extended Range } \\
\text { pH Waterworks }\end{array}$ & Industrial Test Systems & http://www.sensafe.com \\
\hline $\begin{array}{l}\text { Test Strip, Free Cyanide } \\
\text { ReagentStrip }^{\text {TM }}\end{array}$ & Industrial Test Systems & http://www.sensafe.com \\
\hline $\begin{array}{l}\text { Test Strips, Peroxide } \\
\text { Waterworks }^{\mathrm{TM}}\end{array}$ & Industrial Test Systems & http://www.sensafe.com \\
\hline Test Strips, pH Test Strips & ColorpHast $^{\circledR}$ & http://www.labsafety.com \\
\hline $\begin{array}{l}\text { Test Strips, Wastewater } \\
\text { Classifier }\end{array}$ & Spilfyter ${ }^{\circledR}$ & http://www.spilfyter.com \\
\hline
\end{tabular}

